\title{
A pH-, salt- and solvent-responsive carboxymethylcellulose- $g$-poly(sodium acrylate)/medical stone superabsorbent composite with enhanced swelling and responsive properties
}

\author{
W. B. Wang ${ }^{1}$, J. X. Xu ${ }^{1,2}$, A. Q. Wang ${ }^{1, *}$ \\ ${ }^{1}$ Center for Eco-material and Green Chemistry, Lanzhou Institute of Chemical Physics, Chinese Academy of Sciences, \\ Lanzhou 730000, P.R. China \\ ${ }^{2}$ Graduate University of the Chinese Academy of Sciences, Beijing 100049, P.R. China
}

Received 20 August 2010; accepted in revised form 19 November 2010

\begin{abstract}
Free-radical graft copolymerization among sodium carboxymethylcellulose (CMC), partially neutralized acrylic acid (NaA), medical stone (MS) and crosslinker $N, N^{\prime}$-methylene-bis-acrylamide (MBA) was performed to prepare new carboxymethylcellulose-g-poly(sodium acrylate)/medical stone (CMC-g-PNaA/MS) superabsorbent composites. Fourier transform infrared (FTIR) spectra, thermogravimetry- differential scanning calorimetry (TG-DSC) and field emission scanning electromicrsocopic (FESEM) analysis confirmed that NaA had been grafted onto CMC backbone and MS participated in polymerization, and the thermal stability and surface morphologies were improved by the addition of MS. Energy dispersive spectrometer (EDS) and elemental map (EM) analyses revealed the better distribution of MS in the CMC-g-PNaA matrix. The incorporation of $20 \mathrm{wt} \% \mathrm{MS}$ clearly enhanced the water absorption by $100 \%$ (from 317 to $634 \mathrm{~g} / \mathrm{g}$ ). The developed composites showed enhanced swelling rate and On-Off switching swelling characteristics in various pH solutions, saline solutions and hydrophilic organic solvents, which represented interesting and reversible $\mathrm{pH}-$, saline- and hydrophilic organic solvent-responsive characteristics. In addition, the composite exhibited intriguing time-dependent kinetic swelling properties in various heavy metal solutions.
\end{abstract}

Keywords: polymer composites, carboxymethylcellulose, medical stone, superabsorbent, smart-responsive swelling

\section{Introduction}

Organic/inorganic composite materials have unwaveringly been the subject of great interests because they frequently exhibited desired hybrid performance superior to their individual components and cost-efficient characteristics [1-4]. Among them, the composites derived from natural polysaccharides and inorganic clay minerals are especially focused by virtue of their unique commercial and environmental advantages [5], and such materials have also been honored as the material families 'in greening the $21^{\text {st }}$ century materials world' [6].
Superabsorbents are particular 3-D network hydrophilic functional polymer materials that can absorb and conserve considerable amounts of aqueous liquids even under some pressure. Owing to the advantages over conventional absorbents (e.g. sponge, cotton, wood pulp and colloidal silica, etc.), superabsorbents have found potential application in many fields such as agriculture $[7,8]$, hygiene articles [9], wastewater treatment [10-13], carrier of catalyst [14] and drug delivery carrier $[15,16]$, etc. However, most of the practically available superabsorbents are petroleum-based synthetic polymer

\footnotetext{
${ }^{*}$ Corresponding author, e-mail: aqwang@licp.cas.cn
}

(c) BME-PT 
with severe environmental impact and high production cost [17], and so the design and development of eco-friendly superabsorbents by introducing natural raw materials have long been desired.

Thus far, many polysaccharides including starch $[18,19]$, cellulose $[20,21]$, chitosan $[22,23]$, alginate [24], and guar gum [25] etc. have been introduced into superabsorbent for improving the performance and environmentally friendly properties. Compared with other natural polymers, cellulose is the most potential one because it is the most abundant natural polymer with renewable, odourless, non-toxic, biodegradable and biocompatible characteristics [26]. However, cellulose is difficult to be directly modified to produce other useful materials due to its poor solubility and reactivity. Carboxymethylcellulose (CMC) is an anionic carboxymethyl ether of cellulose produced by the alkalicatalyzed reaction of cellulose with chloroacetic acid, which has been widely used as a thickening agent and stabilizing agent in industrial fields. The introduced polar carboxyl groups render the cellulose soluble, chemically reactive and strongly hydrophilic, whereas the connatural odourless, tasteless, nontoxic and biodegradable characteristics of cellulose can be retained. So, CMC is advantageous to fabricate eco-friendly polymer materials by its grafting modification [27], and its application in superabsorbent fields becomes attractive and promising. Medical stone (MS) is a special clay mineral that is different from other clays in both structure and properties. MS is an igneous rock composed of silicic acid, aluminum oxide and above 50 kinds of constant and trace elements, and so it was known as 'health-stone' [28]. The main chemical composition of MS is aluminum metasilicate including $\mathrm{KAlSi}_{3} \mathrm{O}_{8}, \mathrm{NaAlSi}_{3} \mathrm{O}_{8}, \mathrm{CaAl}_{2} \mathrm{Si}_{2} \mathrm{O}_{8}$, $\mathrm{MgAl}_{2} \mathrm{Si}_{2} \mathrm{O}_{8}$ and $\mathrm{FeAl}_{2} \mathrm{Si}_{2} \mathrm{O}_{8}$, etc. In such a structure, silica $\left(\mathrm{SiO}_{2}\right)$ presents regular tetrahedron with a $\left[\mathrm{SiO}_{4}\right]$ configuration, and has a three-dimensional stereo-structure in which aluminum coordinates through oxo-bridging. MS has excellent porosity, multicomponent characteristic, biological activity and safety, and so it shows excellent surface activities, and has been extensively applied in food science, medicine, daily chemical industry, environmental sanitation and wastewater treatment, etc.
[29]. However, few information is available on the application of MS as an inorganic additive for the manufacture of eco-friendly superabsorbent composite materials. So, the composite of $\mathrm{CMC}, \mathrm{NaA}$ and MS was expected to derive superabsorbent materials with improved network structure and swelling properties.

Based on the above background, in the current work, a series of carboxymethylcellulose- $g$-poly (sodium acrylate)/medical stone (CMC- $g$-PNaA/ MS) superabsorbent composites were prepared by the combination of CMC and MS. The structure, thermal stability and morphologies of the developed composites were characterized by Fourier transform infrared spectroscopy (FTIR), thermogravimetric and differential scanning calorimetry analysis (TG-DSC), and field emission scanning electron microscopy (FESEM), energy dispersive spectrometer (EDS) and elemental map (EM) analyses. In addition, the swelling properties, and the stimuli-responsive behaviors of the composite in various medium were evaluated systematically.

\section{Experimental}

\subsection{Materials}

Sodium carboxymethylcellulose (CMC, chemically pure, 300 800 $\mathrm{mPa} \cdot \mathrm{s}\left(25^{\circ} \mathrm{C}\right)$ ) was from Sinopharm Chemical Reagent Co., Ltd, China. Acrylic acid (AA, chemically pure, Shanghai Shanpu Chemical Factory, Shanghai, China) was distilled under reduced pressure before use. Medical stone (MS) micro-powder (Chinese M-Stone Development Co., Ltd, NaiMan, Inner Mongolia, China) was milled and passed through a 320-mesh screen $(<46 \mu \mathrm{m})$ prior to use, and the main chemical composition is $\mathrm{SiO}_{2}, 68.89 \% ; \mathrm{Al}_{2} \mathrm{O}_{3}, 14.06 \% ; \mathrm{Fe}_{2} \mathrm{O}_{3}, 3.61 \% ; \mathrm{K}_{2} \mathrm{O}$, $3.18 \% ; \mathrm{Na}_{2} \mathrm{O}, 4.86 \%$; $\mathrm{CaO}, 1.33 \%$; $\mathrm{MgO}, 2.59 \%$. The Cation Exchange Capacity (CEC) is $9.91 \mathrm{meq} / 100 \mathrm{~g}$, the BET specific surface area is $3.915 \mathrm{~m}^{2} / \mathrm{g}$ and the average pore size is $11.943 \mathrm{~nm}$. Ammonium persulfate (APS, analytical grade, $\mathrm{Xi}^{\prime}$ an Chemical Reagent Factory, China) and $\mathrm{N}, \mathrm{N}$ methylene-bis-acrylamide (MBA, Chemically Pure, Shanghai Chemical Reagent Corp., China) was used as received. All other reagents used were of analytical grade and all solutions were prepared with distilled water. 


\subsection{Preparation of CMC-g-PNaA/MS superabsorbent composites}

CMC (1.04 g) was dissolved in $30 \mathrm{ml}$ of distilled water at $60^{\circ} \mathrm{C}$ in a $250 \mathrm{ml}$ four-necked flask equipped with a mechanical stirrer, a thermometer, a reflux condenser and a nitrogen line to obtain a transparent solution. Afterward, $5 \mathrm{ml}$ of the aqueous solution of the initiator APS $(72 \mathrm{mg}$ ) was added dropwise to the reaction flask under continuous stirring, and kept at $60^{\circ} \mathrm{C}$ for $10 \mathrm{~min}$ to generate radicals. $7.2 \mathrm{~g}$ of AA was pre-neutralized using $8.0 \mathrm{ml}$ of $8.5 \mathrm{M}$ $\mathrm{NaOH}$ solution, and then crosslinker MBA $(21.6 \mathrm{mg})$ and calculated amount of MS powder $(0,0.44,0.93$, $2.08,3.57$ and $5.57 \mathrm{~g}$, respectively) were added under magnetic stirring to form a uniform dispersion. After cooling the reactant to $50^{\circ} \mathrm{C}$, the dispersion was added to the reaction flask, and the temperature was gradually raised to $70^{\circ} \mathrm{C}$ and kept for $3 \mathrm{~h}$ to complete polymerization. Continuous purging of nitrogen was used throughout the reaction period. After being fully washed with distilled water, the obtained gel products were dried to a constant mass at $70^{\circ} \mathrm{C}$, ground and passed through a $40-80$ mesh sieve $(180 \sim 380 \mu \mathrm{m})$.

\subsection{Measurements of equilibrium water absorption and swelling kinetics}

Dry sample (about $0.05 \mathrm{~g}$ ) with the size of 180 $380 \mu \mathrm{m}$ was adequately contacted with excessive aqueous solution at room temperature for $4 \mathrm{~h}$, until a swelling equilibrium was reached. The swollen samples were separated by a 100-mesh screen and then drained on a sieve for $10 \mathrm{~min}$ to remove the excess water. After weighing the swollen samples, the equilibrium water absorption of the superabsorbent was calculated using Equation (1):

$Q_{\mathrm{eq}}=\frac{w_{\mathrm{s}}-w_{\mathrm{d}}}{w_{\mathrm{d}}}$

where $Q_{\mathrm{eq}}[\mathrm{g} / \mathrm{g}]$ is the equilibrium water absorption calculated as grams of water per gram of sample, which are averages of three measurements; $w_{\mathrm{d}}$ and $w_{\mathrm{S}}$ are the weights of the dry sample and waterswollen sample, respectively.

Kinetic swelling behaviors of superabsorbents in each aqueous solution were measured by the following procedure: $0.05 \mathrm{~g}$ samples were immersed in $200 \mathrm{ml}$ of aqueous solution for a set period of time. Then, the swollen gels were filtered using a sieve, and the water absorption $\left(Q_{\mathrm{t}}\right)$ of superabsorbents at a given time $(t)$ can be measured by weighing the swollen and dry samples, and calculated according to Equation (1). In all cases three parallel samples were used and the averages are reported in this paper.

\subsection{Evaluation of pH-responsivity}

The buffer solutions with various $\mathrm{pH}$ values were prepared by combining $\mathrm{KH}_{2} \mathrm{PO}_{4}, \mathrm{~K}_{2} \mathrm{HPO}_{4}, \mathrm{H}_{3} \mathrm{PO}_{4}$ and $\mathrm{NaOH}$ solution properly and the $\mathrm{pH}$ values were determined by a $\mathrm{pH}$ meter (DELTA-320). Ionic strengths of all the buffer solutions were controlled to $0.1 \mathrm{M}$ using $\mathrm{NaCl}$. The equilibrium water absorption $\left(Q_{\text {eq }}\right)$ of the composite in various $\mathrm{pH}$ buffer solutions was measured by a method similar to that in distilled water. The $\mathrm{pH}$-reversibility of the superabsorbent composites was investigated in terms of their swelling and deswelling between $\mathrm{pH}$ 2.0 and 7.2 buffer solution of phosphate. Typically, the sample particle $(0.05 \mathrm{~g}, 180 \sim 380 \mu \mathrm{m})$ was placed in a 100 mesh sieve and adequately contacted with pH 2.0 buffer solution, $154 \mathrm{mmol} / \mathrm{l} \mathrm{LiCl}, \mathrm{NaCl}$ or $\mathrm{KCl}$ solutions and distilled water until reaching equilibrium. Then, the swollen samples were soaked in $\mathrm{pH} 7.2$ buffer solutions, distilled water, and methanol or ethanol for set time intervals. Finally, the swollen samples were filtered, weighed and then calculated the water absorption at a given moment according to the mass change of samples before and after swelling. The consecutive time interval is $15 \mathrm{~min}$ for each cycle, and the same procedure was repeated for four cycles. After every measurement, each solution was renewed.

\subsection{Determination of network parameter $M_{c}$}

The swelling properties of the superabsorbent depend on the crosslinking density, which can be reflected by the average molar mass among the crosslinks, $M_{c}$. $M_{c}$ value is reversibly proportional to crosslinking density and can be calculated by a previously developed method [30, 31]. Typically, $M_{c}$ can be expressed as Equation (2) according to Flory-Huggins theory [32]:

$M_{c}=Q^{5 / 3} \cdot \frac{D_{2} V_{1}}{0.5-X_{1}}$

where $Q$ represents the equilibrium water absorption of the superabsorbent; $D_{2}$ denotes the density 
of superabsorbent; $V_{1}$ denotes the molar volume of the solvent used for swelling studies and $X_{1}$ is the Flory-Huggins interaction parameter between solvent and superabsorbent. Because it is difficult to determine $X_{1}$ by experiment, the linear relationship between $X_{1}$ and $C$ (the volume fractions of methanol in methanol/water mixture) was established to determine $X_{1}$ value (Equation (3)):

$X_{1}=K_{1} C+K_{2}$

After simplified above equations, it was concluded that the relations among each parameter follows Equation (4):

$D_{2} V_{1} Q^{5 / 3}$ methanol-water $=M_{c}\left(0.5-K_{1} C\right)$

The plots of $D_{2} V_{1} Q^{5 / 3}$ methanol-water against $C$ give a set of straight lines, and the $M_{c}$ can be calculated according to the slope of the resulting lines for each superabsorbent.

\subsection{Characterizations}

FTIR spectra were recorded on a Nicolet NEXUS FTIR spectrometer in $4000-400 \mathrm{~cm}^{-1}$ region using $\mathrm{KBr}$ pellets. The composite sample after swelling in various heavy metal solutions was fully washed and dried before FTIR determination. The surface morphologies, energy dispersive spectrometer (EDS) and elemental map (EM) of the samples were examined using a JSM-6701F Field Emission Scanning Electron Microscope (JEOL) after coating the sample with gold film. Thermogravimetric (TG) and Differential scanning calorimetry (DSC) analyses of samples was studied on a Perkin-Elmer TGA-7 thermogravimetric analyzer (Perkin-Elmer Cetus Instruments, Norwalk, CT), with a temperature range of $25-700^{\circ} \mathrm{C}$ at a heating rate of $10^{\circ} \mathrm{C} / \mathrm{min}$ using dry nitrogen purge at a flow rate of $50 \mathrm{ml} / \mathrm{min}$. The samples were dried at $100^{\circ} \mathrm{C}$ for $4 \mathrm{~h}$ to remove the absorbed water before determining TG-DSC curves.

\section{Results and discussion}

\subsection{FTIR spectra analysis}

As shown in Figure 1, the characteristic absorption bands of CMC at 1061, 1118 and $1162 \mathrm{~cm}^{-1}$ (stretching vibration of $\mathrm{C}-\mathrm{OH}$ groups) were obviously weakened after reaction and shifted to 1056, 1111 and $1169 \mathrm{~cm}^{-1}$ for CMC- $g$-PNaA. The new bands at $1714 \mathrm{~cm}^{-1}$ ( $\mathrm{C}=\mathrm{O}$ stretching of $-\mathrm{COOH}$ groups), $1568 \mathrm{~cm}^{-1}$ (asymmetrical stretching vibration of $-\mathrm{COO}^{-}$groups), 1454 and $1409 \mathrm{~cm}^{-1}$ (symmetrical stretching vibration of $-\mathrm{COO}^{-}$groups) appeared in the spectrum of CMC-g-PNaA (Figure 1b). This result indicates that $\mathrm{NaA}$ monomers were grafted onto CMC backbone. Compared with the spectrum of $\mathrm{CMC}-\mathrm{g}-\mathrm{PNaA}$, the $-\mathrm{C}=\mathrm{O}$ stretching of $-\mathrm{COOH}$ groups at $1714 \mathrm{~cm}^{-1}$ shifted to $1715 \mathrm{~cm}^{-1}$, and the asymmetrical stretching of $-\mathrm{COO}^{-}$groups at $1568 \mathrm{~cm}^{-1}$ shifted to $1572 \mathrm{~cm}^{-1}$ after forming composite. The stretching vibration of $(\mathrm{Si}) \mathrm{O}-\mathrm{H}$ at

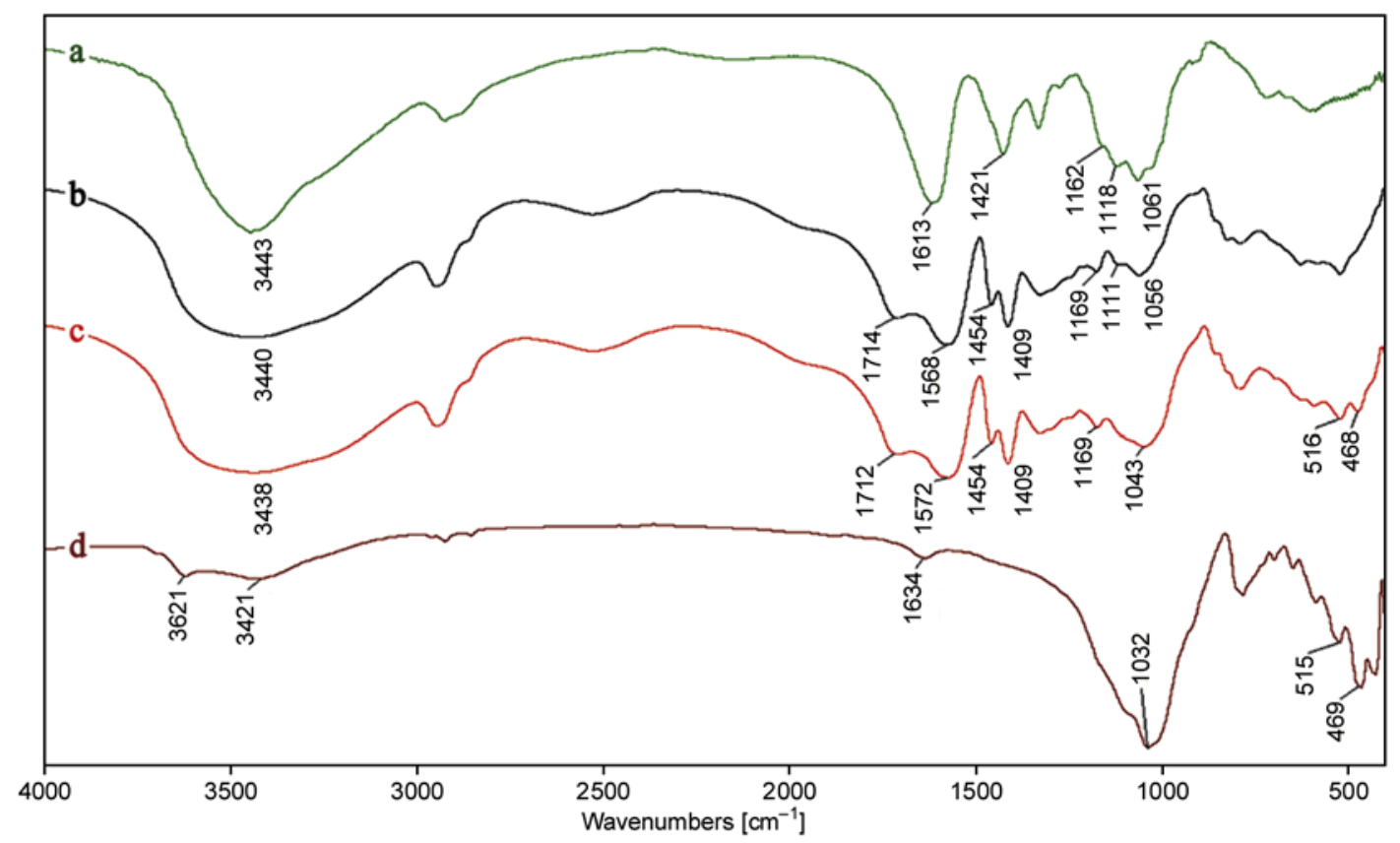

Figure 1. FTIR spectra of (a) CMC, (b) CMC-g-PNaA, (c) CMC-g-PNaA/MS (20 wt\%), and (d) MS 


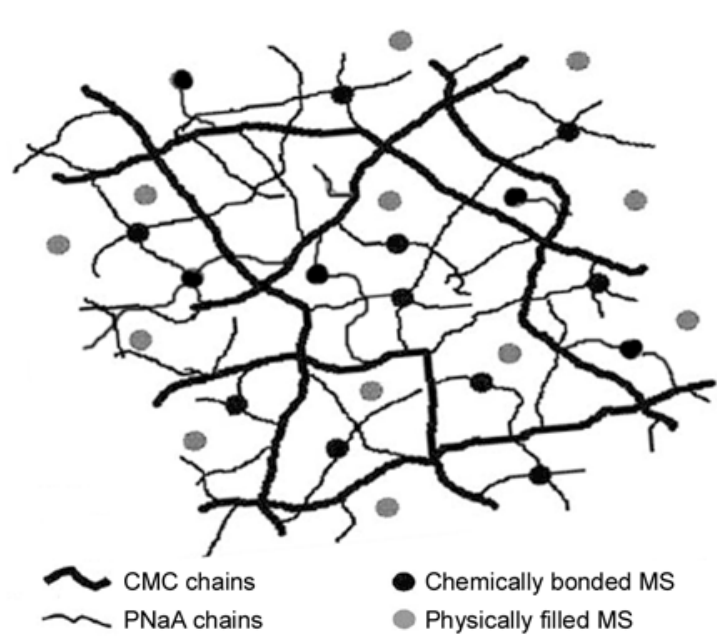

Figure 2. Schematic representation of the CMC- $g-\mathrm{PNaA} /$ MS superabsorbent composite

$3621 \mathrm{~cm}^{-1}$ can almost not be observed in the spectrum of CMC- $g$-PNaA/MS (Figure 1c, d). The $\mathrm{Si}-\mathrm{O}$ stretching vibration of MS at $1032 \mathrm{~cm}^{-1}$ shifted to $1043 \mathrm{~cm}^{-1}$ after forming composite, but its intensity was obviously weakened. The $\mathrm{Si}-\mathrm{O}$ bending vibration at $468 \mathrm{~cm}^{-1}$ can be observed in the spectrum of $\mathrm{CMC}-\mathrm{g}-\mathrm{PNaA} / \mathrm{MS}$ with weakened intensity. This information gives direct evidence that MS participated in the graft copolymerization reaction through its active silanol groups [33-35]. Moreover, a schematic structure illustration of the CMC- $g$-PNaA/ MS superabsorbent composite is presented in Figure 2, the MS existed in the polymer matrix can be classified as two kinds: chemically bonding and physically filling [35].

\subsection{TG-DSC analyses}

Figure 3 showed the TG-DSC curves of CMC- $g$ $\mathrm{PNaA}$ hydrogel and CMC- $g$-PNaA/MS (20 wt\%) composite. It is obvious that introduction of MS exhibited great influence on the thermal behaviors of the superabsorbents. The weight loss about $6.4 \mathrm{wt} \%$ below $251^{\circ} \mathrm{C}$ for CMC-g-PNaA (corresponding to an endothermic step at $248^{\circ} \mathrm{C}$ ) and about $4.9 \mathrm{wt} \%$ below $254.7^{\circ} \mathrm{C}$ for CMC-g-PNaA/ MS (corresponding to an endothermic step at $253^{\circ} \mathrm{C}$ ) can be ascribed to the removal of water absorbed, the dehydration of saccharide rings in the chain of CMC [36]. The successive weight loss about $20.4 \mathrm{wt} \%\left(251 \sim 432^{\circ} \mathrm{C}\right)$ for CMC- $g$-PNaA and about $17.3 \mathrm{wt} \%\left(255 \sim 436^{\circ} \mathrm{C}\right)$ for $\mathrm{CMC}-g$ $\mathrm{PNaA} / \mathrm{MS}$ can be attributed to the breaking of $\mathrm{C}-\mathrm{O}-\mathrm{C}$ bonds in $\mathrm{CMC}$ chains (corresponding to the

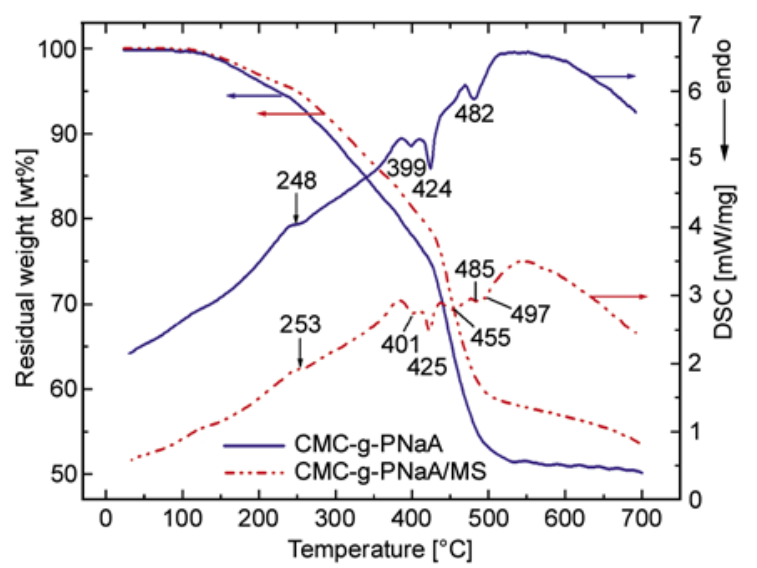

Figure 3. TG-DSC curves of CMC- $g$-PNaA and CMC- $g$ $\mathrm{PNaA} / \mathrm{MS}(20 \mathrm{wt} \%)$

endothermic peaks at $399^{\circ} \mathrm{C}$ for $\mathrm{CMC}-g$-PNaA and $401^{\circ} \mathrm{C}$ for $\mathrm{CMC}-g$-PNaA/MS) and the elimination of water molecule derived from the two neighboring carboxylic groups of the grafted $\mathrm{PNaA}$ chains due to the formation of anhydride (corresponding to the endothermic peak at $424^{\circ} \mathrm{C}$ for CMC- $g$-PNaA and $425^{\circ} \mathrm{C}$ for CMC-g-PNaA/MS) [37]. However, the endothermic peak of CMC- $g$-PNaA/MS at $425^{\circ} \mathrm{C}$ is obviously weaker than that of CMC-g$\mathrm{PNaA}$, and the new endothermic peak at $455^{\circ} \mathrm{C}$ also appeared in the DSC curve of CMC- $g$-PNaA/MS. This indicates that the thermal decomposition process in this region was relieved by introducing MS. The weight losses about $20.1 \mathrm{wt} \%$ from 432 to $502^{\circ} \mathrm{C}$ for CMC-g-PNaA (corresponding to a sharp endothermic peak at $482^{\circ} \mathrm{C}$ ) and about $19.1 \mathrm{wt} \%$ from 436 to $504^{\circ} \mathrm{C}$ for $\mathrm{CMC}-g$-PNaA/MS (corresponding to the continuous endothermic peak from 485 to $497^{\circ} \mathrm{C}$ ) are due to the breakage of main-chain scission and the destruction of crosslinked network structure. Compared with the sharp endothermic peak of CMC- $g$-PNaA, the appearance of continuous endothermic peak in the DSC curve of CMC- $g$ $\mathrm{PNaA} / \mathrm{MS}$ reveals that the thermal decomposition of the superabsorbent was delayed after incorporating MS. As described above, CMC-g-PNaA/MS composite exhibited slower weight-loss and thermal decomposition rate as well as lesser total weight loss than CMC-g-PNaA, which indicated the incorporation of MS improved the thermal stability of superabsorbent.

\subsection{FESEM, EDS and EM analyses}

Figure 4 showed the FESEM micrographs of CMC$g$-PNaA, MS and CMC- $g$-PNaA/MS (20 and $40 \mathrm{wt} \%$ ) 

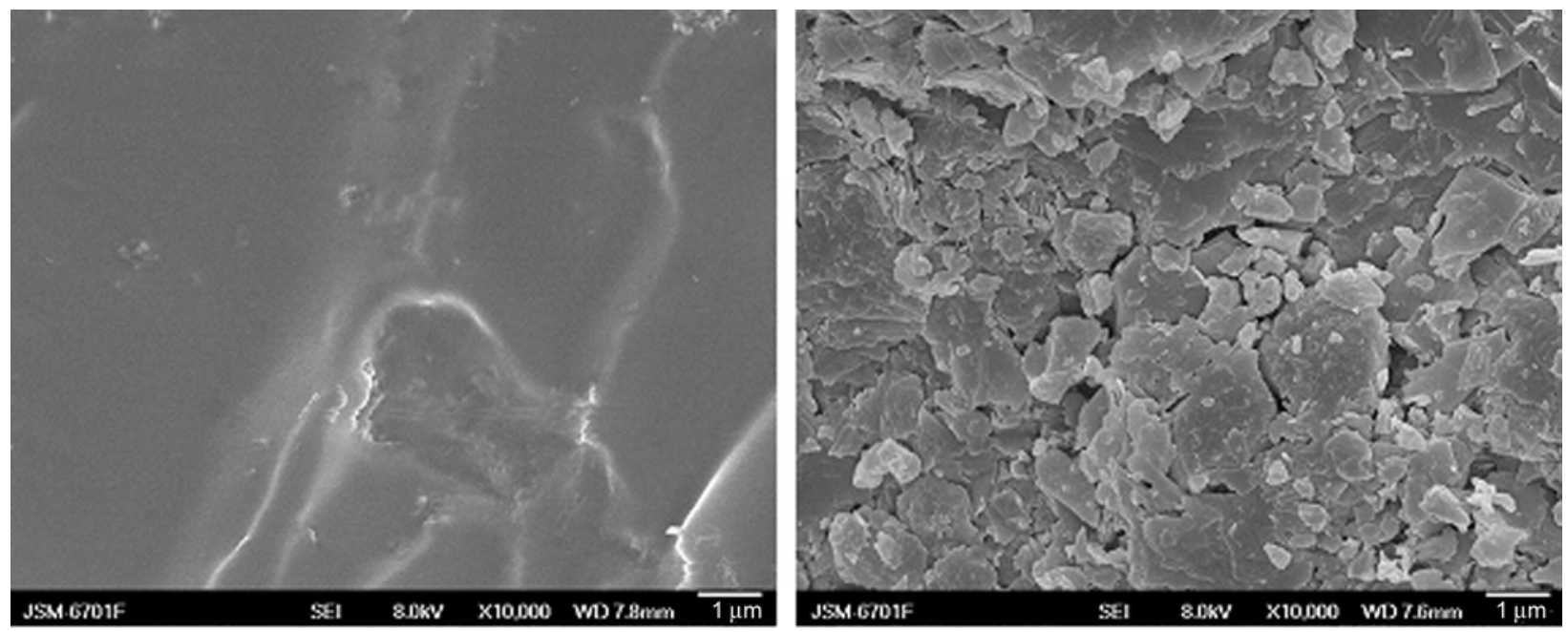

b)

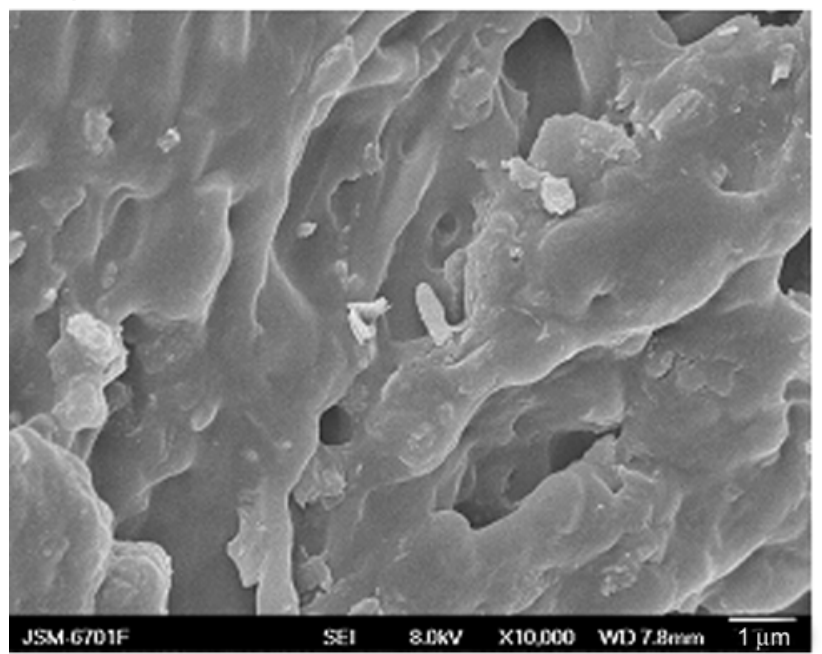

c)

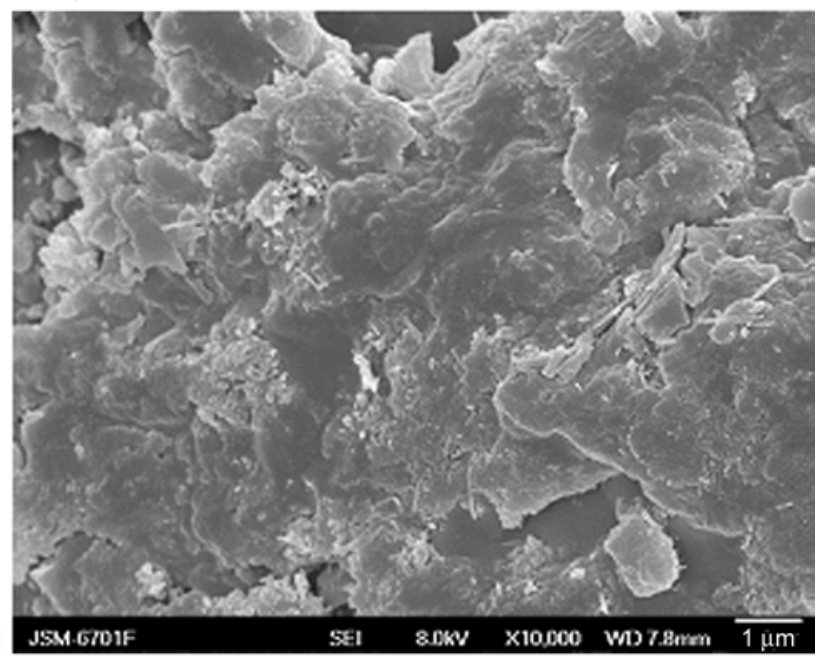

d)

Figure 4. FESEM micrographs of (a) CMC- $g$-PNaA, (b) MS, (c) CMC- $g$-PNaA/MS (20 wt \%), and (d) CMC- $g$-PNaA/MS $(40 \mathrm{wt} \%)$

superabsorbent composite. As can be seen, CMC- $g$ $\mathrm{PNaA}$ only has a smooth and dense morphology (Figure 4a), and MS shows a correspondingly coarse and sheet surface morphology (Figure 4b). After compounding MS with CMC-g-PNaA, the surface roughness of the superabsorbent was obviously increased and some pores and gap can be observed (Figure 4c), and the surface roughness of CMC-g$\mathrm{PNaA} / \mathrm{MS}$ increased with increasing the content of MS (Figure 4d), which implies that introduction of MS contributes to improve the surface morphology of the resultant composite. In addition, this observation gives a direct revelation that MS was uniformly dispersed and almost embedded within the polymer matrix without the flocculation of MS particles, and formed a homogeneous combination of MS with the matrix network.
Figure 5 shows the EDS spectrograms of CMC-gPNaA, MS and CMC-g-PNaA/MS (20 and $40 \mathrm{wt} \%$ ), corresponding to the surface of samples shown in Figure 4a-4d). As can be seen, only the characteristic peaks of $\mathrm{C}, \mathrm{O}$ and $\mathrm{Na}$ elements can be observed in the EDS spectrogram of CMC-g-PNaA. After forming $\mathrm{CMC}-\mathrm{g}$-PNaA/MS composites, the $\mathrm{Si}, \mathrm{Al}$, $\mathrm{K}, \mathrm{Ca}, \mathrm{Fe}, \mathrm{Na}$ and $\mathrm{Mg}$ elements ascribed to $\mathrm{MS}$ (Figure 5b) can also be observed, indicating that MS was distributed in the polymer matrix. For further proving this, the elemental maps (EM) for each sample were examined and are shown in Figure 6. It can be noticed that the characteristic $\mathrm{O}, \mathrm{Si}, \mathrm{Al}, \mathrm{K}$, $\mathrm{Ca}, \mathrm{Fe}, \mathrm{Na}$ and $\mathrm{Mg}$ elements of MS clearly appeared in the elemental map of the composites, and these elements showed equal distribution in the CMC- $g$ $\mathrm{PNaA}$ matrix. This result is consistent with the 


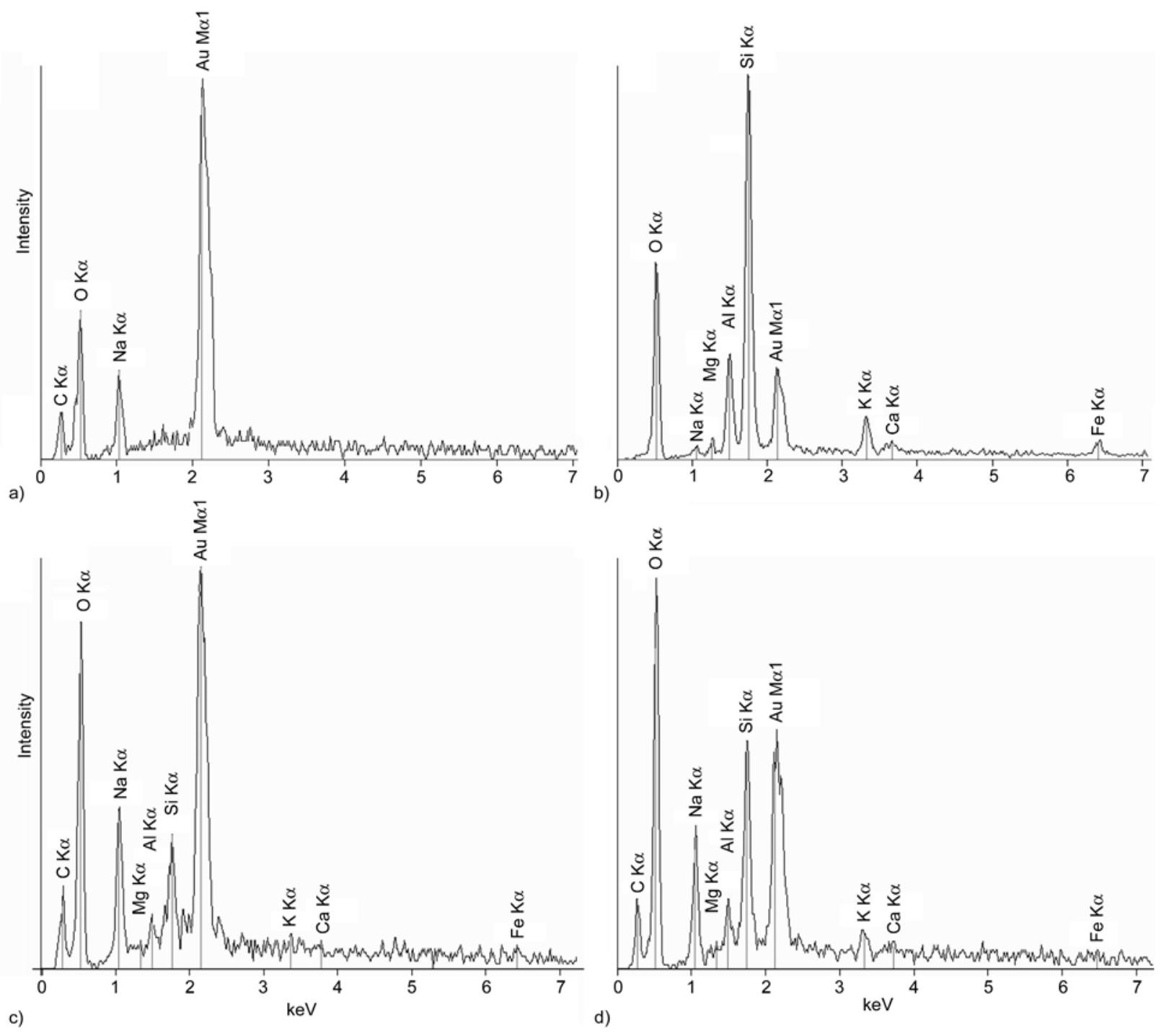

Figure 5. EDS curves of (a) CMC- $g$-PNaA, (b) MS, (c) CMC- $g$-PNaA/MS (20 wt $\%$ ) and (d) CMC- $g$-PNaA/MS (40 wt $\%$ )

FESEM observations and EDS results, and reveals the uniform composite of CMC- $g$-PNaA matrix with MS.

\subsection{Effects of MS content on $M_{c}$ and water absorption}

As shown in Figure 7, the $M_{c}$ of the superabsorbent composite firstly increased and then decreased with increasing the content of MS. A similar tendency can be observed for the water absorption curves of the superabsorbents. The water absorption sharply increased with increasing the content of MS until a maximum absorption $(634 \mathrm{~g} / \mathrm{g}$ in distilled water and $60 \mathrm{~g} / \mathrm{g}$ in $0.9 \mathrm{wt} \% \mathrm{NaCl}$ solution) was achieved at $20 \mathrm{wt} \% \mathrm{MS}$, and then decreased with further increasing MS content. In comparison with the MS-free superabsorbent hydrogel, the water absorption of the composite increased by $99 \%$ after incorporating $20 \mathrm{wt} \%$ of MS. This observation indicates that the water absorption of the superabsorbent is mainly dependent on the crosslinking density. The obvious enhancement of water absorption can be attributed to the following reasons: (1) MS may participate in polymerization reaction and act as additional crosslinker. As a result, the polymer network structure was improved and the network void for holding was regularly formed, and the water absorption capacity of the superabsorbent was improved [35, 38]; (2) MS can ionize and release lots of metal cations in contact with water [29], which increased the concentration of electrolyte in interior gel network and enhanced the osmotic pressure difference between gel network and swelling media, and so the water absorption can be enhanced; (3) ionization of 
a)

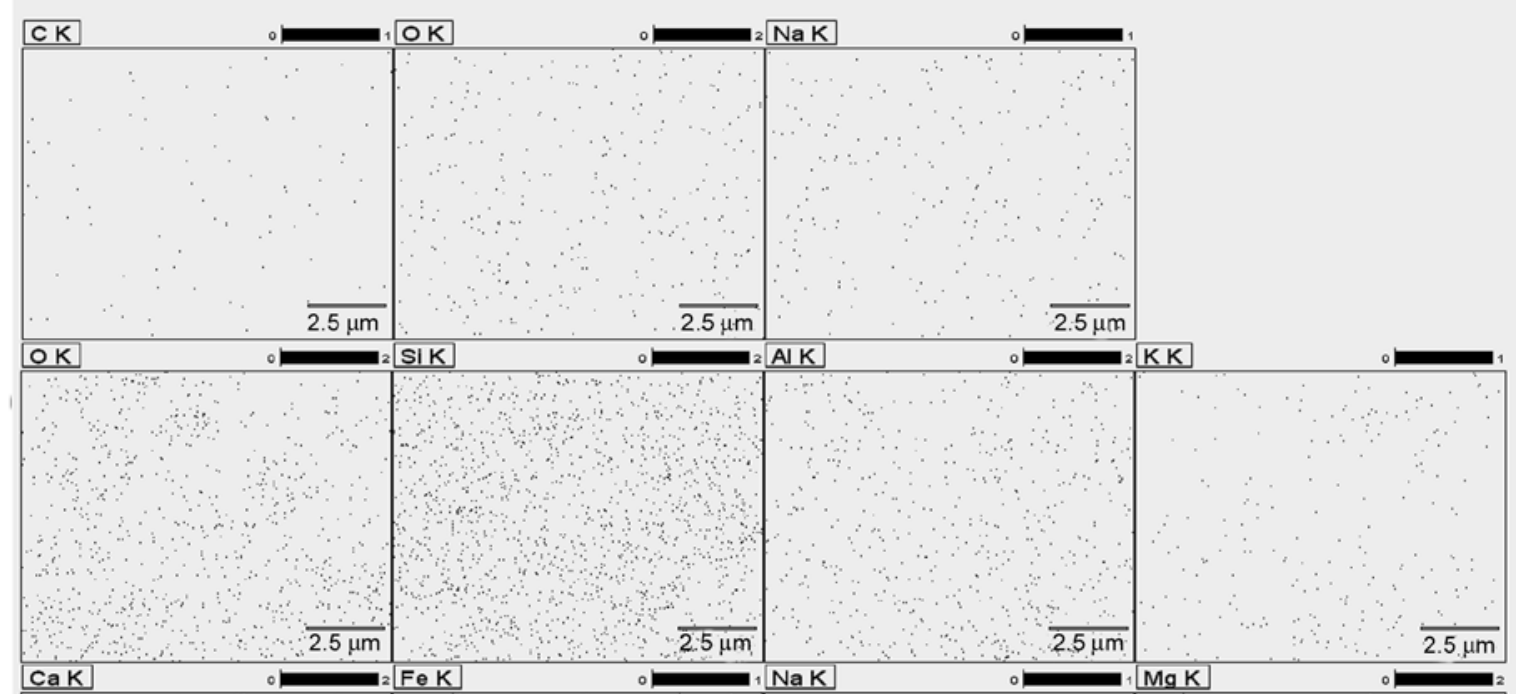

b)

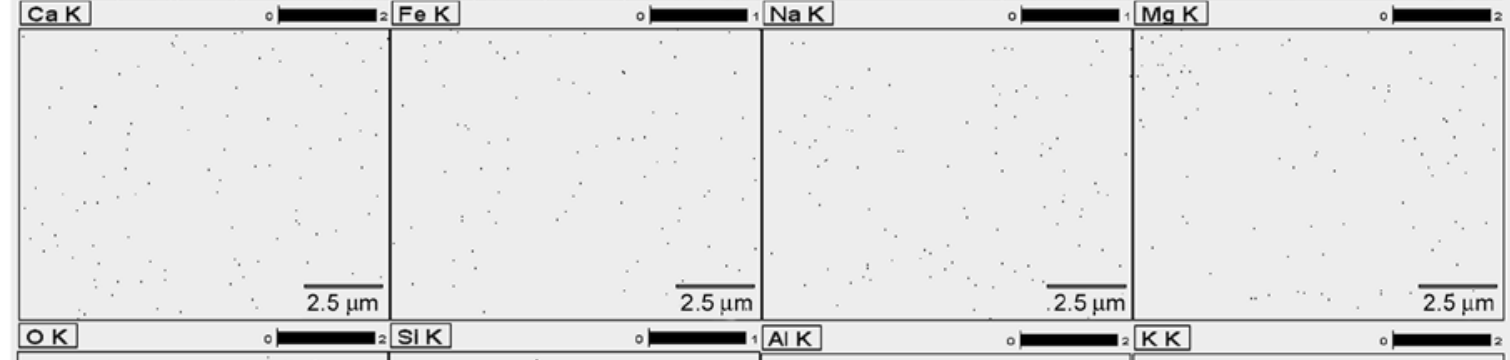

c)
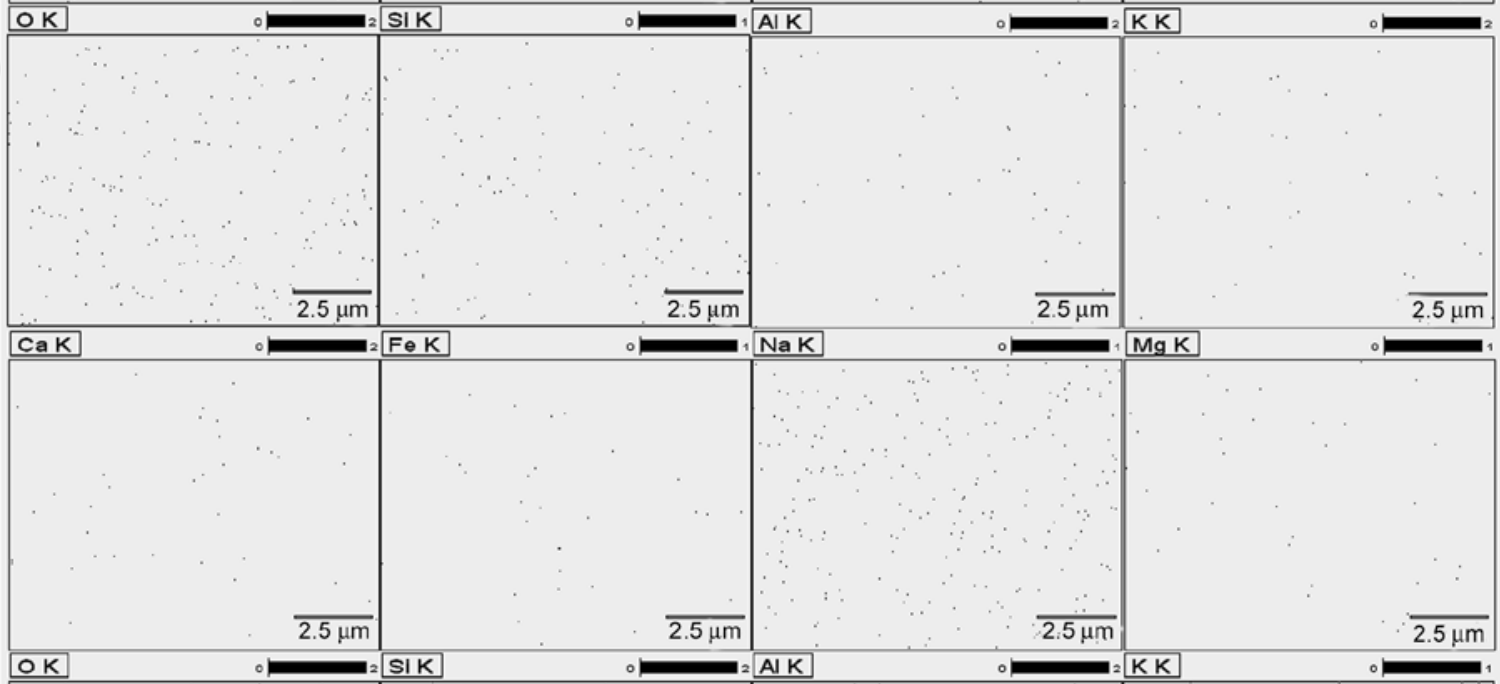

d)

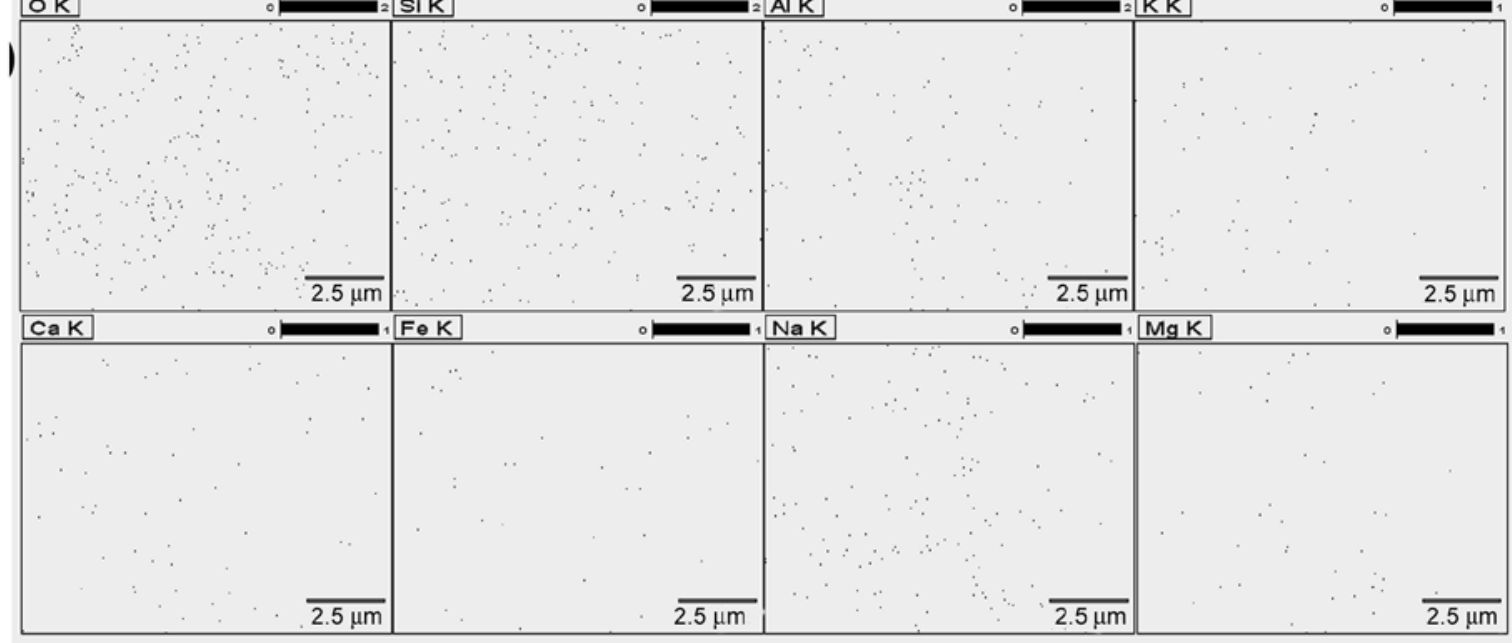

Figure 6. Element area profiles of (a) CMC- $g$-PNaA, (b) MS, (c) CMC- $g$-PNaA/MS (20 wt \%) and (d) CMC- $-\mathrm{PNaA} / \mathrm{MS}$ $(40 \mathrm{wt} \%)$ at the magnification of $10000 \times$. The small dots denote the distribution of each element in the polymeric matrix 

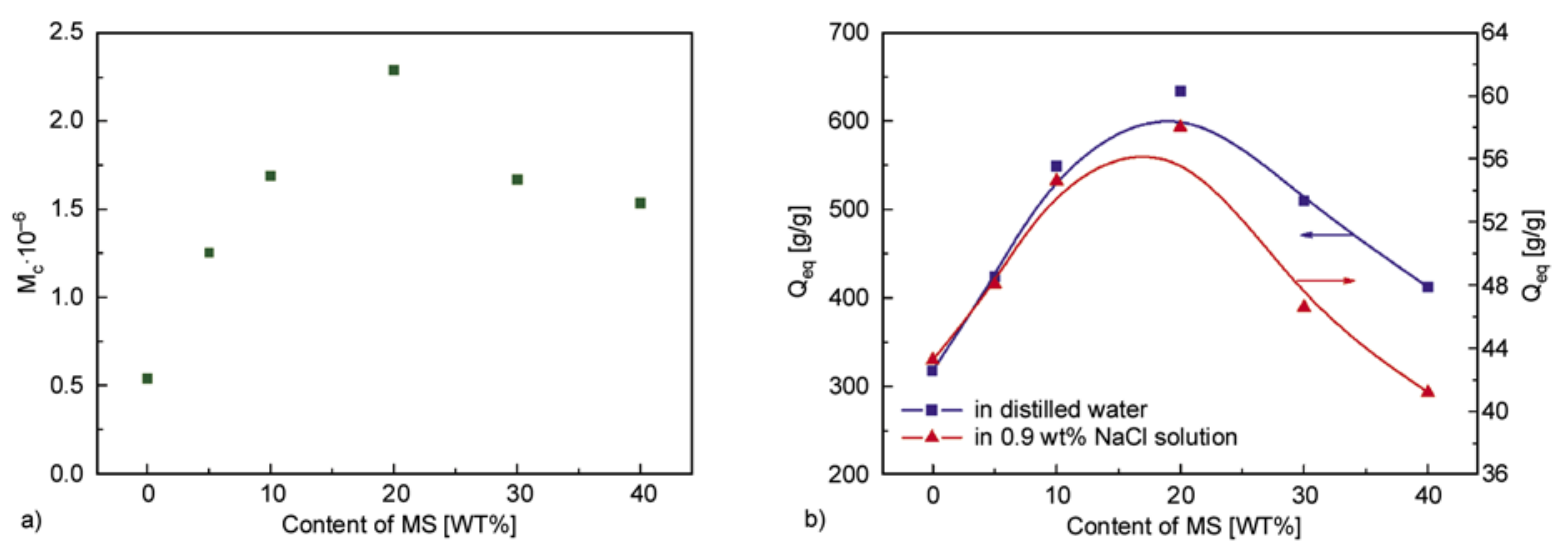

Figure 7. Effects of MS content on $M_{\mathrm{c}}$ (a) and water absorption (b)

MS may generate [-SiO] ${ }^{-}$groups [29], which can repulse with the negatively charged graft polymer chains and facilitate to the expansion of gel network, and thus contribute to improve the water absorption. However, the excessive addition of MS induced a decrease of water absorption. Because the excessive MS particles may physically fill in the polymer network, which may plug up the network voids for holding water and decrease the hydrophilicity of the composite. For this reason, the water absorption decreased with the increase of the MS content above $20 \mathrm{wt} \%$. It deserves to be mentioned that the water absorption of the composite is till higher than the hydrogel without MS even the content of MS reached $40 \mathrm{wt} \%$, which is extremely favorable to reduce the production cost.

\subsection{Swelling kinetics in distilled water}

Kinetic swelling curves of the superabsorbents in distilled water were depicted in Figure 8. It can be noticed that the water absorption sharply increased

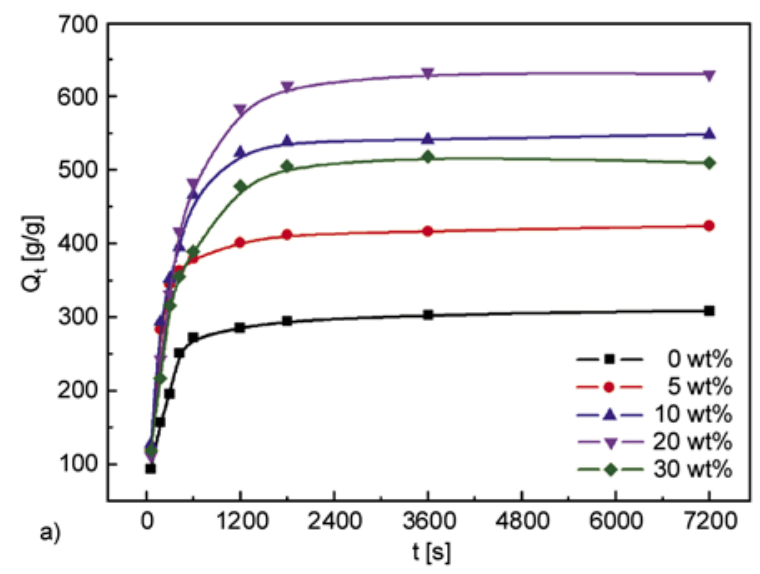

with prolonging contact time at initial stage $(<1200 \mathrm{~s})$, and then the increasing trend becomes flatter until swelling equilibrium was reached (about $1800 \mathrm{~s}$ ). In this section, Schott's pseudo second order kinetics model was used to evaluate the swelling kinetics of the superabsorbents (Equation (5)) [39]:

$\frac{t}{Q_{\mathrm{t}}}=\frac{1}{K_{\mathrm{is}}}+\frac{1}{Q_{\infty}} t$

where $Q_{\mathrm{t}}$ is the water absorption at a set swelling time $t$ [s]; $Q_{\infty}$ is the theoretical equilibrium water absorption $[\mathrm{g} / \mathrm{g}] ; K_{\text {is }}$ is the initial swelling rate constant $[\mathrm{g} /(\mathrm{g} \cdot \mathrm{s})]$. As shown in Figure $8 \mathrm{~b})$, the plots of $t / Q_{\mathrm{t}}$ against $t$ showed straight lines with better linear correlation coefficient, indicating that the kinetic swelling behaviors of the superabsorbents follow the pseudo second order model. The values of $K_{\text {is }}$, $Q_{\infty}$ and swelling rate constant $K_{\mathrm{s}}\left(=K_{\mathrm{is}} / Q_{\mathrm{eq}}{ }^{2},[\mathrm{~g} /(\mathrm{g} \cdot \mathrm{s})]\right)$ can be determined by fitting experimental data using Equation (5) and calculated by the slope and intercept of the straight lines (Table 1). According

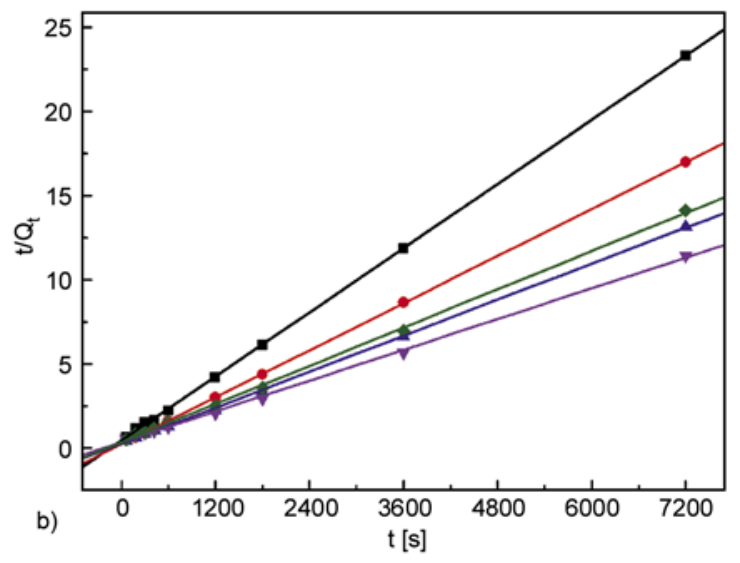

Figure 8. Swelling kinetic curves of the superabsorbents in distilled water (a) and the plots of $t / Q_{\mathrm{t}}$ against $t$ for each superabsorbent (b) 
Table 1. Swelling kinetic parameters for CMC- $g$-PNaA/MS composites with various amounts of MS

\begin{tabular}{|l|c|c|c|c|c|}
\hline \multicolumn{1}{|c|}{ Samples } & $\boldsymbol{Q}_{\text {eq }}[\mathbf{g} / \mathbf{g} \mathbf{g}$ & $\boldsymbol{Q}_{\infty}[\mathbf{g} / \mathbf{g}]$ & ${ }^{*} \boldsymbol{K}_{\text {is }}[\mathbf{g} /(\mathbf{g} \cdot \mathbf{s})]$ & ${ }^{* * *} \boldsymbol{K}_{\mathbf{s}} \cdot \mathbf{1 0} \mathbf{0}^{-\mathbf{5}}[\mathbf{g} /(\mathbf{g} \cdot \mathbf{s})]$ & $\mathbf{R}$ \\
\hline CMC- $g$-PNaA & 318 & 315 & 2.2783 & 2.2530 & 0.9999 \\
\hline CMC-g-PNaA/MS (5 wt\%) & 424 & 429 & 4.6092 & 2.5639 & 0.9999 \\
\hline CMC-g-PNaA/MS (10 wt\%) & 549 & 562 & 3.8069 & 1.2631 & 0.9998 \\
\hline CMC-g-PNaA/MS (20 wt\%) & 633 & 648 & 2.8820 & 0.7193 & 0.9995 \\
\hline CMC- $g$-PNaA/MS (30 wt\%) & 514 & 529 & 2.8636 & 1.0839 & 0.9995 \\
\hline
\end{tabular}

"Initial swelling rate constant $K_{\mathrm{is}} ;{ }^{* *}$ Swelling rate constant $K_{\mathrm{s}}=K_{\mathrm{is}} / Q_{\mathrm{eq}}{ }^{2}$

to the resultant data, it can be concluded that the initial swelling rate of the superabsorbents decreased in the order of CMC- $g$-PNaA/MS $(5 \mathrm{wt} \%)>\mathrm{CMC}-$ $g$-PNaA/MS $(10 \mathrm{wt} \%)>$ CMC- $g$-PNaA/MS $(20 \mathrm{wt} \%)$ $>$ CMC-g-PNaA/MS $(30 \mathrm{wt} \%)>$ CMC-g-PNaA. This result reveals that incorporation of MS also enhanced the initial water absorption rate of the superabsorbents besides water absorption capability. It can also be noticed that the swelling rate constant $\left(K_{\mathrm{s}}\right)$ in the whole swelling process follow the order of CMC- $g$-PNaA/MS $(5 \mathrm{wt} \%)>\mathrm{CMC}-g$ $\mathrm{PNaA}>\mathrm{CMC}-\mathrm{g}-\mathrm{PNaA} / \mathrm{MS}(10 \mathrm{wt} \%)>\mathrm{CMC}-g-$ $\mathrm{PNaA} / \mathrm{MS}(30 \mathrm{wt} \%)>\mathrm{CMC}-\mathrm{g}$-PNaA/MS $(20 \mathrm{wt} \%)$, indicating the moderate introduction of MS ( $5 \mathrm{wt} \%)$ is favorable to improve the swelling rate. However, the change trend of $K_{\mathrm{s}}$ is not consistent with that of $K_{\text {is. }}$ This is because that the water absorption $\left(Q_{\text {eq }}\right)$ of the superabsorbent composites with 10, 20 and $30 \mathrm{wt} \%$ of MS is higher than CMC- $g$-PNaA hydrogel. This means that the polymer chains need to move greater distance for reaching the swelling equilibrium, so the time of reaching equilibrium for CMC- $g$-PNaA/MS (10, 20 and $30 \mathrm{wt} \%)$ is relatively longer than that of $\mathrm{CMC}-g-\mathrm{PNaA}$.

\section{6. $\mathrm{pH}$-responsive characteristics}

It can be noticed from Figure 9 that the water absorption of the composite is almost zero at $\mathrm{pH} 2.0$ for both CMC-g-PNaA hydrogel and CMC- $g$-PNaA/ MS composite, but the water absorption rapidly increased with enhancing the $\mathrm{pH}$ of external solution, and almost keep constant in the $\mathrm{pH}$ range of 612. The water absorption follows the order of CMC- $g$-PNaA/MS $(20 \mathrm{wt} \%)>\mathrm{CMC}-g$-PNaA/MS $(10 \mathrm{wt} \%)>\mathrm{CMC}-g-\mathrm{PNaA} / \mathrm{MS}(30 \mathrm{wt} \%)>\mathrm{CMC}-$ $g-\mathrm{PNaA}$ at $\mathrm{pH}$ 7.2. In acidic medium, the $-\mathrm{COO}^{-}$ groups on the polymer chain converted to $-\mathrm{COOH}$ groups. For one thing, the electrostatic repulsion among negatively charged $-\mathrm{COO}^{-}$groups decreased and the expansion of polymer network was restricted; for another, the increase of number of $-\mathrm{COOH}$

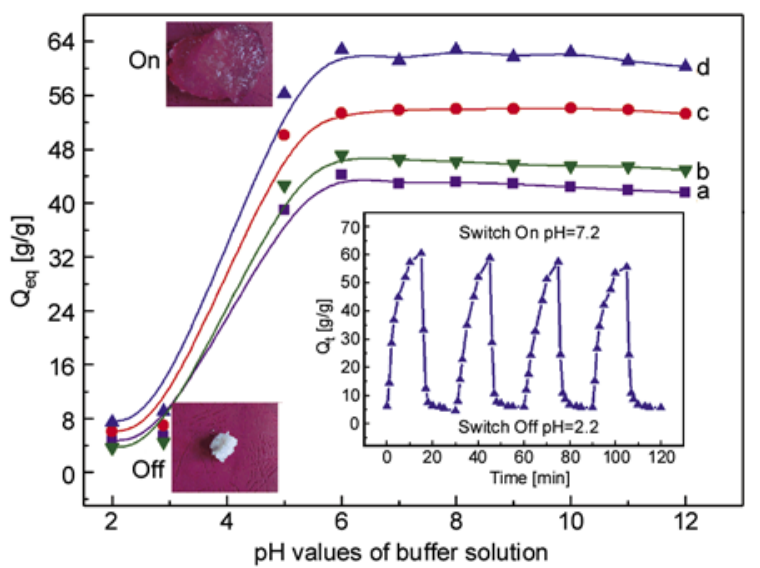

Figure 9. Variation of swelling ratio for (a) $\mathrm{CMC}-g-\mathrm{PNaA}$, (b) $\mathrm{CMC}-g-\mathrm{PNaA} / \mathrm{MS}$ (30 wt $\%$ ), (c) CMC- - $\mathrm{PNaA} / \mathrm{MS}$ (10 wt $\%$ ) and (d) CMC- $g-\mathrm{PNaA} / \mathrm{MS}$ (20 wt $\%$ ) superabsorbents at the buffer solution with various $\mathrm{pHs}$. The inset is the On-Off switching behavior as reversible pulsatile swelling $(\mathrm{pH}=7.2)$ and deswelling $(\mathrm{pH}=2.0)$ of CMC- $g$ $\mathrm{PNaA} / \mathrm{MS}$ (20 wt $\%$ ) composite. The time interval between $\mathrm{pH}$ changes is $15 \mathrm{~min}$.

groups strengthened the intramolecular and intermolecular hydrogen bonding interaction and enhanced the physical crosslinking degree. Thus, the polymer network swells little at low $\mathrm{pH}$. For evaluating the reversibility of $\mathrm{pH}$-responsivity, the swellingdeswelling cycles were evaluated between the buffer solutions of $\mathrm{pH} 2.0$ (Off) and 7.2 (On). It can be obviously observed that the composite shrunken at $\mathrm{pH} 2.0$ can recover to relatively higher swelling ratio at $\mathrm{pH}$ 7.2. After four swelling-deswelling periods between $\mathrm{pH} 2.0$ and 7.2, the intriguing On-Off switchable and reversible swelling effect was observed. This implies that the $\mathrm{pH}$-responsivity of the superabsorbent composite is highly reversible and the introduction of MS effectively enhanced the responsivity of the superabsorbent.

\subsection{Salt-responsive characteristics}

Figure 10 depicts the circular swelling-deswelling behaviors of the superabsorbent composite between distilled water and $154 \mathrm{mmol} / \mathrm{l}$ of $\mathrm{LiCl}, \mathrm{NaCl}$ and 


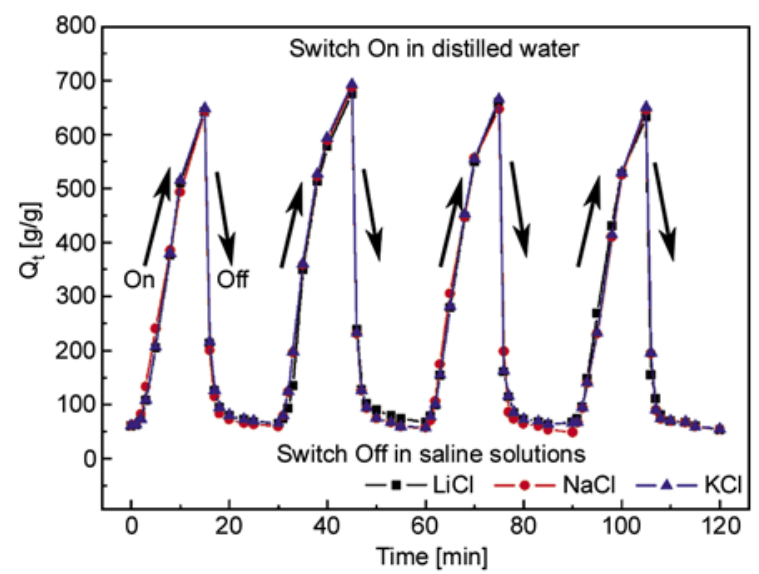

Figure 10. The reversible On-Off switching swelling behaviors of the composite between distilled and $154 \mathrm{mmol} / \mathrm{l}$ of $\mathrm{LiCl}, \mathrm{NaCl}$ and $\mathrm{KCl}$ solutions

$\mathrm{KCl}$ solutions. As can be seen, the water-swollen superabsorbent composite can shrink and loss the absorbed water when it was contacted with salt solutions, but the shrunken gel can rapidly recovered in distilled water. The switching salt stimuliresponsive characteristics were observed. As well known, the osmotic pressure difference between internal gel network and external swelling media acts as the driving force for the swelling of superabsorbent; it decreases with adding polyelectrolyte to the solution. Also, the ultimate screen effects of cations on negative charges of polymer chains increased with increasing polyelectrolyte in the solution. These factors induced the deswelling of the composite. After four circles of swelling (On)deswelling (Off), the superabsorbent still keeps excellent responsive properties, indicating the swelling of the superabsorbent is switched and reversible.

\subsection{Hydrophilic organic solvents-responsive characteristics}

The phase transitions of hydrogels have aroused attention since the collapse of polyacrylamide hydrogels in aqueous solution of acetone was observed [40]. The unique phase transition behavior of superabsorbent to organic solvents endows it with stimuli-responsive characteristics. Figure 11 represents the swelling (On)-deswelling (Off) cyclic curves of the superabsorbent composite between distilled water (On) and methanol or ethanol (Off). It was noticed that the composite exhibited higher water absorption in distilled water, but the absorbed water was sharply lost when it was fully contacted with

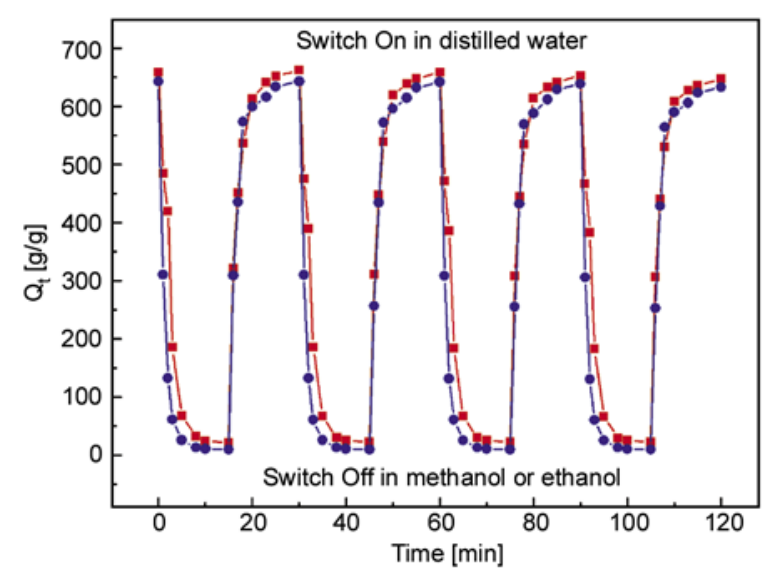

Figure 11. The reversible On-Off swelling behaviors of the composite between distilled water and methanol or ethanol

hydrophilic organic solvent. The great shrinkage of the water absorption in hydrophilic organic solvents can be attributed to the decrease of the solubility parameter and dielectric constant as well as the interaction between the polar groups of organic solvent and the ionic groups in the polymer [41]. The solubility parameter of water is $23.4\left(\mathrm{cal} / \mathrm{cm}^{3}\right)^{1 / 2}$, but the value of methanol and ethanol is only 14.5 and $12.7\left(\mathrm{cal} / \mathrm{cm}^{3}\right)^{1 / 2}$. The great decrease of solubility parameter caused the rapid shrinkage of water absorption [42]. Likewise, the dielectric constant of water is 78.54 , but the dielectric constant of methanol and ethanol is only 32.63 and 24.3. As described previously [41], the dielectric constant of the solution directly affects the ionization degree of ionic groups, and the larger the dielectric constant of the solution, the bigger the osmotic pressure of the gel. Thus, the sharp decrease of dielectric constant from hydrophilic organic solvents to water certainly causes the reduction of water absorption. In addition, the polarity of water is larger than methanol and ethanol. The lower polarity of ethanol and methanol is responsible for the easier collapse of composite network in contrast to water [43]. These indicate that the collapse of the composite is a result of the total depletion of water due to the competitive extraction of water from the solvated polymeric network. It can also be observed from Figure 11 that the shrunken gel can rapidly recovered when it was immersed in distilled water, and no obvious slack after four On-Off cycles. This indicates that the hydrophilic organic solvent-responsive properties of the composite are switching and reversible. 


\subsection{Time-dependent characteristics in heavy-metal solutions}

Effects of heavy metal saline solutions on kinetic swelling behaviors of the composite were evaluated in $\mathrm{NiCl}_{2}, \mathrm{CuCl}_{2}$ and $\mathrm{ZnCl}_{2}$ solutions at the concentration of 2, 5 and $10 \mathrm{mmol} / \mathrm{l}$ (Figure 12). An intriguing time-dependent swelling behavior was observed for the composite in each saline solution. The water absorption of the composite increased with prolonging contact time, reached a maximum absorption $(127,63$ and $40 \mathrm{~g} / \mathrm{g}$ for 2,5 and $10 \mathrm{mmol} / 1$ of $\mathrm{Ni}^{2+} ; 126,65$ and $39 \mathrm{~g} / \mathrm{g}$ for 2,5 and $10 \mathrm{mmol} / \mathrm{l}$ of $\mathrm{Cu}^{2+}$; and 130,70 and $41 \mathrm{~g} / \mathrm{g}$ for 2,5 and $10 \mathrm{mmol} / 1$ of $\mathrm{Zn}^{2+}$, respectively) with further prolonging contact time and then decreased until the swelling almost disappeared. Also, the required time of reaching the maximum absorption was reduced with increasing the concentration of saline solution (12, 8 and $5 \mathrm{~min}$ for 2,5 and $10 \mathrm{mmol} / 1$ of each saline solution, respectively). The time-dependent swelling effect can be attributed to the following reasons depicted in Figure 13. The superabsorbent composite contains numerous $-\mathrm{COOH}$ and $-\mathrm{COO}^{-}$ functional groups, which can complex with heavy metal cations to form an additional ionic crosslinking $[12,44]$. So the effective crosslinking degree of composite network increased with prolonging the contact time. Also, the complex of $-\mathrm{COO}^{-}$with heavy metal cations would decrease electrostatic repulsion among negatively charged polymer chains and reduce the expansion degree of the hydrogel network. As a result, the absorbed water would be expelled out from the network void and the swollen hydrogel tends to shrink. After reaching the maximum swelling, the swollen composite network gradually collapsed and the initially absorbed water was squeezed out of the network under this action. For proving the complex action, the FTIR spectra of the composite after swelling in $5 \mathrm{mmol} / 1 \mathrm{NiCl}_{2}$, $\mathrm{CuCl}_{2}$ and $\mathrm{ZnCl}_{2}$ solutions for 0.5, 5. 10. 30 and 120 min were determined and are shown in Figure 14. As can be seen, the characteristic absorption bands of $-\mathrm{COO}^{-}$groups at $1572 \mathrm{~cm}^{-1}$ (Figure 1c) shifted to $1571\left(\mathrm{Ni}^{2+}, 0.5 \mathrm{~min}\right), 1568\left(\mathrm{Ni}^{2+}, 5 \mathrm{~min}\right)$, $1561\left(\mathrm{Ni}^{2+}, 10 \mathrm{~min}\right), 1558\left(\mathrm{Ni}^{2+}, 30 \mathrm{~min}\right)$ and $1556 \mathrm{~cm}^{-1}\left(\mathrm{Ni}^{2+}, 120 \mathrm{~min}\right)$; to $1570\left(\mathrm{Cu}^{2+}, 0.5 \mathrm{~min}\right)$, $1569\left(\mathrm{Cu}^{2+}, 5 \mathrm{~min}\right), 1563\left(\mathrm{Cu}^{2+}, 10 \mathrm{~min}\right), 1560\left(\mathrm{Cu}^{2+}\right.$, $30 \mathrm{~min})$ and $1557 \mathrm{~cm}^{-1}\left(\mathrm{Cu}^{2+}, 120 \mathrm{~min}\right)$; to 1571
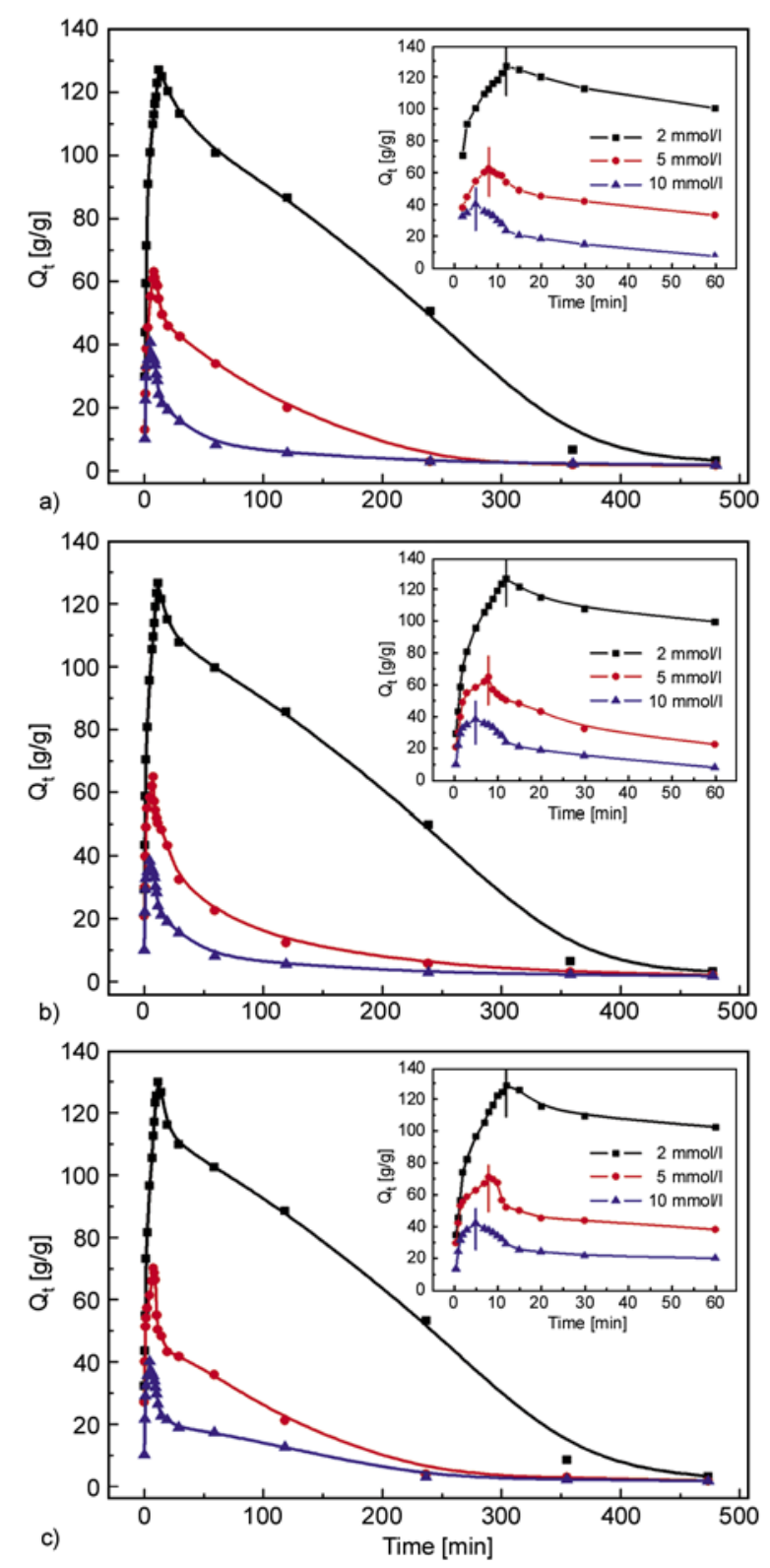

Figure 12. Kinetic swelling curves of CMC- $g$-PNaA/MS (20 wt\%) in 2, 5 and $10 \mathrm{mmol} / 1$ of (a) $\mathrm{NiCl}_{2}$, (b) $\mathrm{CuCl}_{2}$ and (c) $\mathrm{ZnCl}_{2}$ solutions. The insets are the enlargement of the curves ranged from 0 $60 \mathrm{~min}$.

$\left(\mathrm{Zn}^{2+}, 5 \mathrm{~min}\right), 1570\left(\mathrm{Zn}^{2+}, 10 \mathrm{~min}\right), 1568\left(\mathrm{Zn}^{2+}\right.$, $30 \mathrm{~min})$ and $1563 \mathrm{~cm}^{-1}\left(\mathrm{Zn}^{2+}, 120 \mathrm{~min}\right)$ after swelling in heavy metal saline solutions for different interval, respectively. The shift of absorption band to low wavenumber indicates that $\mathrm{Ni}^{2+}, \mathrm{Cu}^{2+}$ and $\mathrm{Zn}^{2+}$ ions were complexed with $-\mathrm{COO}^{-}$groups [44] and the additional crosslinking in hydrophilic network was formed, and so the swollen gel network tends to deswell. 


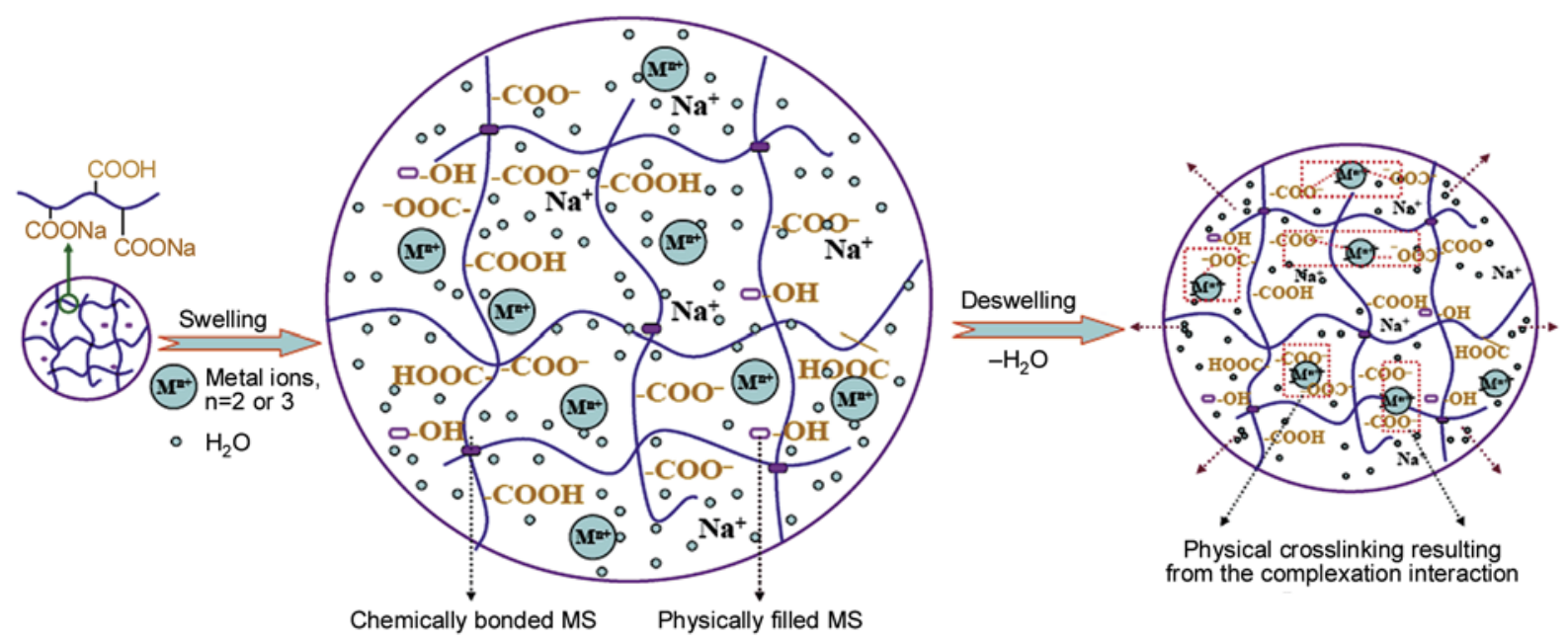

Figure 13. Proposed mechanism for the swelling-deswelling of the composite in heavy metal solutions
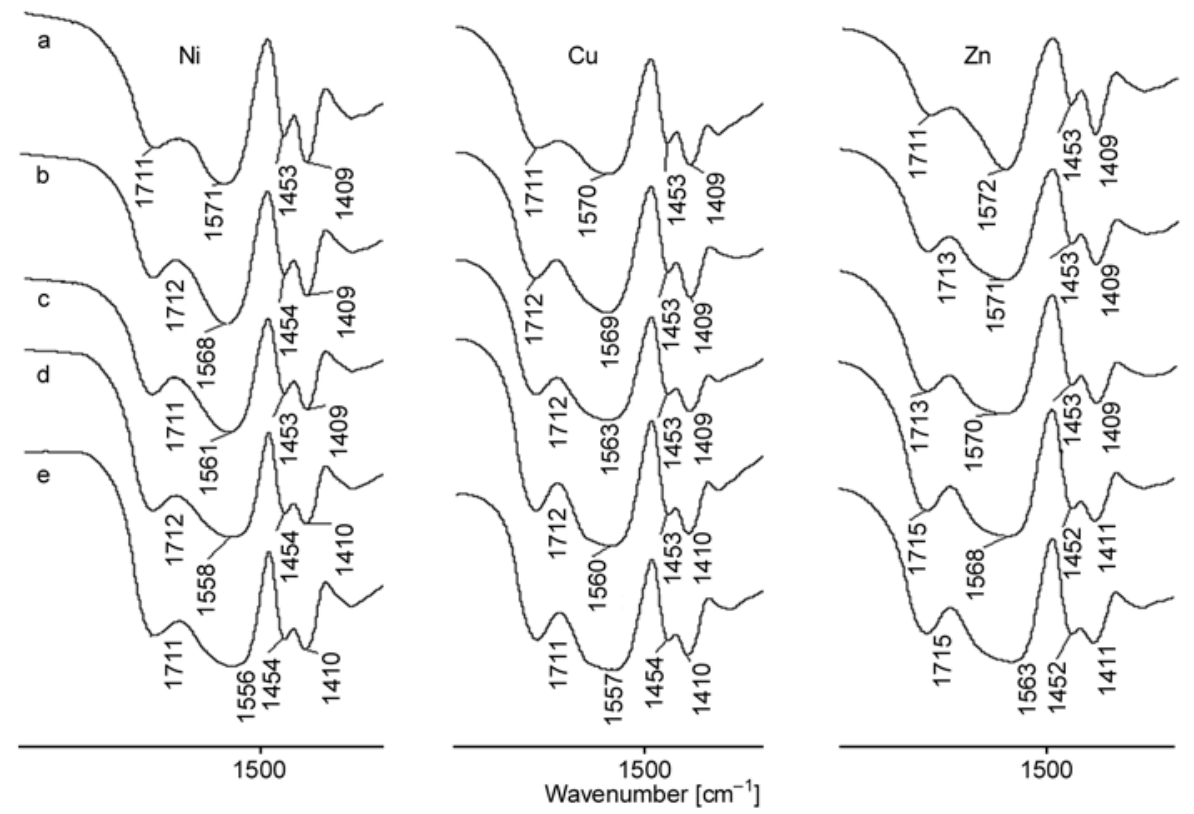

Figure 14. FTIR spectra of the superabsorbent composite after swelling in $5 \mathrm{mmol} / 1 \mathrm{NiCl}_{2}, \mathrm{CuCl}_{2}$ and $\mathrm{ZnCl}_{2}$ solutions for (a) $0.5 \mathrm{~min}$, (b) $5 \mathrm{~min}$, (c) $10 \mathrm{~min}$, (d) $30 \mathrm{~min}$, (e) $120 \mathrm{~min}$

\section{Conclusions}

For developing new kinds of superabsorbent composites with improved structure, properties and environmentally friendly characteristics, reducing the excessive consumption of petroleum resource and minimizing the pollution from the industrial polymers, a series of cellulose-based superabsorbent composites containing MS were prepared by free-radical graft copolymerization technique. FTIR analysis revealed that the NaA monomers had been grafted onto the macromolecular chains of $\mathrm{CMC}$, and MS participated in the polymer reaction and combined with the network by chemically crosslinking and physically filling models. MS led to a better dispersion in the $\mathrm{CMC}-\mathrm{g}$-PNaA matrix as shown by EDS and EM analyses. The incorporation of MS and the formation of composite structure clearly improved the surface morphologies, thermal stability, swelling capabilities, and swelling rate of the developed composite. The superabsorbent composite exhibited excellent switching swellingdeswelling behaviors between $\mathrm{pH} 2.0$ and 7.2 buffer solution, between distilled water and $154 \mathrm{mmol} / \mathrm{l}$ $\mathrm{LiCl}, \mathrm{NaCl}$ and $\mathrm{KCl}$ solutions, between distilled water and hydrophilic organic solvents, and the obvious $\mathrm{pH}$-responsive, saline-responsive and hydrophilic organic solvent-responsive properties were presented. In addition, the intriguing time- 
dependent swelling behaviors were observed in various heavy metal saline solutions, which are caused by the strong complexation action between hydrophilic $-\mathrm{COO}^{-}$groups and heavy metal ions. As described above, the superabsorbent composite based on renewable, low-cost and biodegradable natural $\mathrm{CMC}$ and abundant MS exhibited improved swelling properties, excellent $\mathrm{pH}$-responsive, saltreversible, hydrophilic organic solvent-reversible properties and intriguing time-dependent swelling behavior, which can be used as potential candidate for water-manageable materials or drug delivery system.

\section{Acknowledgements}

The authors thank for jointly supporting by the National Natural Science Foundation of China (No. 20877077) and 1863' Project of the Ministry of Science and Technology, P. R. China (No. 2006AA100215).

\section{References}

[1] Paul D. R., Robeson L. M.: Polymer nanotechnology: Nanocomposites. Polymer, 49, 3187-3204 (2008). DOI: $10.1016 /$ j.polymer.2008.04.017

[2] Utracki L. A., Sepehr M., Boccaleri E.: Synthetic, layered nanoparticles for polymeric nanocomposites (PNCs). Polymers for Advanced Technologies, 18, 137 (2007).

DOI: $10.1002 /$ pat.852

[3] Dalaran M., Emik S., Güçlü G., İyim T. B., Özgümüş S.: Removal of acidic dye from aqueous solutions using poly(DMAEMA-AMPS-HEMA) terpolymer/ MMT nanocomposite hydrogels. Polymer Bulletin, 63, 159-171 (2009).

DOI: $10.1007 / \mathrm{s} 00289-009-0077-4$

[4] Zhang J. P., Wang A. Q.: Synergistic effects of $\mathrm{Na}^{+}$montmorillonite and multi-walled carbon nanotubes on mechanical properties of chitosan film. Express Polymer Letters, 3, 302-308 (2009). DOI: 10.3144/expresspolymlett.2009.38

[5] Šimkovic I.: What could be greener than composites made from polysaccharides? Carbohydrate Polymers, 74, 759-762 (2008). DOI: $10.1016 /$ j.carbpol.2008.07.009

[6] Ray S. S., Bousmina M.: Biodegradable polymers and their layered silicate nanocomposites: In greening the $21^{\text {st }}$ century materials world. Progress in Materials Science, 50, 962-1079 (2005). DOI: $10.1016 /$ j.pmatsci.2005.05.002
[7] Teodorescu M., Lungu A., Stanescu P. O., Neamtu C.: Preparation and properties of novel slow-release NPK agrochemical formulations based on poly(acrylic acid) hydrogels and liquid fertilizers. Industrial and Engineering Chemistry Research, 48, 6527-6534 (2009). DOI: $10.1021 /$ ie900254b

[8] Mahdavinia G. R., Mousavi S. B., Karimi F., Marandi G. B., Garabaghi H., Shahabvand S.: Synthesis of porous poly(acrylamide) hydrogels using calcium carbonate and its application for slow release of potassium nitrate. Express Polymer Letters, 3, 279-285 (2009).

DOI: 10.3144/expresspolymlett.2009.35

[9] Das A., Kothari V. K., Makhija S., Avyaya K.: Development of high-absorbent light-weight sanitary napkin. Journal of Applied Polymer Science, 107, 14661470 (2008). DOI: 10.1002/app.26936

[10] Güçlü G., Al E., Emik S., İyim T. B., Özgümüş S., Özyürek M.: Removal of $\mathrm{Cu}^{2+}$ and $\mathrm{Pb}^{2+}$ ions from aqueous solutions by starch-graft-acrylic acid/montmorillonite superabsorbent nanocomposite hydrogels. Polymer Bulletin, 65, 333-346 (2010). DOI: $10.1007 / \mathrm{s} 00289-009-0217-\mathrm{x}$

[11] Guilherme M. R., Reis A. V., Paulino A. T., Fajardo A. R., Muniz E. C., Tambourgi E. B.: Superabsorbent hydrogel based on modified polysaccharide for removal of $\mathrm{Pb}^{2+}$ and $\mathrm{Cu}^{2+}$ from water with excellent performance. Journal of Applied Polymer Science, 105, 29032909 (2007).

DOI: $10.1002 / a p p .26287$

[12] Tang Q., Sun X., Li Q., Wu J., Lin J.: Synthesis of polyacrylate/polyethylene glycol interpenetrating network hydrogel and its sorption of heavy-metal ions. Science and Technology of Advanced Materials, 10, 015002/1-015002/7 (2009).

DOI: $10.1088 / 1468-6996 / 10 / 1 / 015002$

[13] Kaşgöz H., Durmus A.: Dye removal by a novel hydrogel-clay nanocomposite with enhanced swelling properties. Polymers for Advanced Technologies, 19, 838-845 (2008).

DOI: $10.1002 /$ pat. 1045

[14] Tang Q., Lin J., Wu Z., Wu J., Huang M., Yang Y.: Preparation and photocatalytic degradability of $\mathrm{TiO}_{2} /$ polyacrylamide composite. European Polymer Journal, 43, 2214-2220 (2007).

DOI: $10.1016 /$ j.eurpolymj.2007.01.054

[15] Sadeghi M., Hosseinzadeh H.: Synthesis of starchpoly(sodium acrylate-co-acrylamide) superabsorbent hydrogel with salt and $\mathrm{pH}$-responsiveness properties as a drug delivery system. Journal of Bioactive and Compatible Polymers, 23, 381-404 (2008). DOI: $10.1177 / 0883911508093504$ 
[16] Pourjavadi A., Barzegar S.: Synthesis and evaluation of $\mathrm{pH}$ and thermosensitive pectin-based superabsorbent hydrogel for oral drug delivery systems. StarchStärke, 61, 161-172 (2009).

DOI: $10.1002 /$ star.200800063

[17] Kiatkamjornwong S., Mongkolsawat K., Sonsuk M.: Synthesis and property characterization of cassava starch grafted poly[acrylamide-co-(maleic acid)] superabsorbent via $\gamma$-irradiation. Polymer, 43, 3915-3924 (2002).

DOI: $10.1016 / \mathrm{S} 0032-3861(02) 00224-0$

[18] Nakason C., Wohmang T., Kaesaman A., Kiatkamjornwong S.: Preparation of cassava starch-graft-polyacrylamide superabsorbents and associated composites by reactive blending. Carbohydrate Polymers, 81, 348357 (2010).

DOI: 10.1016/j.carbpol.2010.02.030

[19] Al E., Güçlü G., Banu İyimT., Emik S., Özgümüş S.: Synthesis and properties of starch-graft-acrylic acid/Namontmorillonite superabsorbent nanocomposite hydrogels. Journal of Applied Polymer Science, 109, 16-22 (2008).

DOI: $10.1002 /$ app.27968

[20] Demitri C., Sole R. D., Scalera F., Sannino A., Vasapollo G., Maffezzoli A., Ambrosio L., Nicolais L.: Novel superabsorbent cellulose-based hydrogels crosslinked with citric acid. Journal of Applied Polymer Science, 110, 2453-2460 (2008).

DOI: 10.1002/app. 28660

[21] Pourjavadi A., Amini-Fazl M. S., Ayyari M.: Optimization of synthetic conditions CMC-g-poly(acrylic acid)/Celite composite superabsorbent by Taguchi method and determination of its absorbency under load. Express Polymer Letters, 1, 488-494 (2007).

DOI: 10.3144/expresspolymlett.2007.69

[22] Mahdavinia G. R., Pourjavadi A., Hosseinzadeh H., Zohuriaan M. J.: Modified chitosan 4. Superabsorbent hydrogels from poly(acrylic acid-co-acrylamide) grafted chitosan with salt- and $\mathrm{pH}$-responsiveness properties. European Polymer Journal, 40, 1399-1407 (2004).

DOI: $10.1016 /$ j.eurpolymj.2004.01.039

[23] Chen Y., Liu Y-F., Tan H-M., Jiang J-X.: Synthesis and characterization of a novel superabsorbent polymer of $\mathrm{N}, \mathrm{O}$-carboxymethyl chitosan graft copolymerized with vinyl monomers. Carbohydrate Polymers, 75, 287292 (2009).

DOI: $10.1016 /$ j.carbpol.2008.07.022

[24] Pourjavadi A., Ghasemzadeh H., Soleyman R.: Synthesis, characterization, and swelling behavior of alginate-g-poly(sodium acrylate)/kaolin superabsorbent hydrogel composites. Journal of Applied Polymer Science, 105, 2631-2639 (2007).

DOI: $10.1002 / a p p .26345$
[25] Wang W. B., Zhang J. P., Wang A. Q.: Preparation and swelling properties of superabsorbent nanocomposites based on natural guar gum and organo-vermiculite. Applied Clay Science, 46, 21-26 (2009).

DOI: 10.1016/j.clay.2009.07.001

[26] Kim J., Yun S., Ounaies Z.: Discovery of cellulose as a smart material. Macromolecules, 39, 4202-4206 (2006). DOI: $10.1021 / \mathrm{ma} 060261 \mathrm{e}$

[27] Pourjavadi A., Zohuriaan-Mehr M. J., Ghasempoori S. N., Hossienzadeh H.: Modified CMC. V. Synthesis and super-swelling behavior of hydrolyzed CMC-gPAN hydrogel. Journal of Applied Polymer Science, 103, 877-883 (2007).

DOI: $10.1002 / a p p .25224$

[28] Yang Z. L.: Health stone- An introduction on medical stone (in Chinese). Information on Traditional Chinese Medicine, 4, 31 (1986).

[29] Li J., Zhang P-Y., Gao Y., Song X-G., Dong J-H.: Overview of Maifanshi: Its physi-chemical properties and nutritious function in drinking water. Environmental Science and Technology (China), 31, 63-66 (2008).

[30] Li G. Q., Lin J. M., Wu J. H.: Determination of crosslinkage density and its influence on water absorbency for superabsorbents (in Chinese). Journal of Huaqiao University (National Science), 21, 264267 (2000).

[31] Li X., Xu S. M., Wang J. D., Chen X. Z., Feng S.: Structure and characterization of amphoteric semi-IPN hydrogel based on cationic starch. Carbohydrate Polymers, 75, 688-693 (2009).

DOI: $10.1016 /$ j.carbpol.2008.09.009

[32] Flory P. J.: Principles of polymer chemistry. Cornell University Press, New York (1953).

[33] Li A., Wang A. Q., Chen J. M.: Studies on poly(acrylic acid)/attapulgite superabsorbent composite. I. Synthesis and characterization. Journal of Applied Polymer Science, 92, 1596-1603 (2004).

DOI: $10.1002 /$ app. 20104

[34] Wu J. H., Lin J. M., Li G. Q., Wei C. R.: Influence of the $\mathrm{COOH}$ and $\mathrm{COONa}$ groups and crosslink density of poly(acrylic acid)/montmorillonite superabsorbent composite on water absorbency. Polymer International, 50, 1050-1053 (2001).

DOI: $10.1002 /$ pi.728

[35] Wu J. H., Wei Y. L., Lin J. M., Lin S. B.: Study on starch-graft-acrylamide/mineral powder superabsorbent composite. Polymer, 44, 6513-6520 (2003). DOI: $10.1016 / \mathrm{S} 0032-3861(03) 00728-6$

[36] Yang F., Li G., He Y-G., Ren F-X., Wang G-X.: Synthesis, characterization, and applied properties of carboxymethyl cellulose and polyacrylamide graft copolymer. Carbohydrate Polymers, 78, 95-99 (2009). DOI: $10.1016 /$ j.carbpol.2009.04.004 
[37] Huang Y. H., Lu J., Xiao C. B.: Thermal and mechanical properties of cationic guar gum/poly(acrylic acid) hydrogel membranes. Polymer Degradation and Stability, 92, 1072-1081 (2007).

DOI: $10.1016 /$ j.polymdegradstab.2007.02.011

[38] Pourjavadi A., Hosseinzadeh H., Sadeghi M.: Synthesis, characterization and swelling behavior of gelatin$g$-poly(sodium acrylate)/kaolin superabsorbent hydrogel composites. Journal of Composite Materials, 41, 2057-2069 (2007).

DOI: $10.1177 / 0021998307074125$

[39] Schott H.: Swelling kinetics of polymers. Journal of Macromolecular Science Part B: Physics, 31, 1-9 (1992).

DOI: $10.1080 / 00222349208215453$

[40] Tanaka T.: Collapse of gels and the critical endpoint. Physical Review Letters, 40, 820-823 (1978). DOI: 10.1103/PhysRevLett.40.820

[41] Liu Y., Xie J-J., Zhu M-F., Zhang X-Y.: A study of the synthesis and properties of AM/AMPS copolymer as superabsorbent. Macromolecular Materials and Engineering, 289, 1074-1078 (2004).

DOI: $10.1002 /$ mame.200400154
[42] Kabiri K., Zohuriaan-Mehr M. J., Mirzadeh H., Kheirabadi M. J.: Solvent-, ion- and pH-specific swelling of poly(2-acrylamido-2-methylpropane sulfonic acid) superabsorbing gels. Journal of Polymer Research, 17, 203-212 (2010). DOI: $10.1007 / \mathrm{s} 10965-009-9306-7$

[43] Zhang J. P., Liu Y., Wang A. Q.: Study on superabsorbent composite XXV. Synthesis, characterization, and swelling behaviors of poly(acrylic acid-co-Nacryloylmorpholine)/attapulgite superabsorbent composites. Polymer Composites, 31, 691-699 (2010). DOI: $10.1002 /$ pc.20845

[44] Zhang J. P., Chen H., Li P., Wang A. Q.: Study on superabsorbent composite, 14. Preparation of poly (acrylic acid)/organo-attapulgite composite hydrogels and swelling behaviors in aqueous electrolyte solution. Macromolecular Materials and Engineering, 291, 1529-1538 (2006).

DOI: $10.1002 / \mathrm{mame} .200600317$ 